\title{
Effect of Leptin on Chronic Inflammatory Disorders: Insights to Therapeutic Target to Prevent Further Cardiovascular Complication
}

\author{
Gashaw Dessie (D) \\ Birhanu Ayelign (iD ${ }^{2}$ \\ Yonas Akalu iD ${ }^{3}$ \\ Tewodros Shibabaw (D) \\ Meseret Derbew Molla (iD) \\ 'Department of Biochemistry, School of \\ Medicine, College of Medicine and Health \\ Sciences, University of Gondar, Gondar, \\ Ethiopia; ${ }^{2}$ Department of Immunology \\ and Molecular Biology, School of \\ Biomedical and Laboratory Science, \\ College of Medicine and Health Sciences, \\ University of Gondar, Gondar, Ethiopia; \\ ${ }^{3}$ Department of Physiology, School of \\ Medicine, College of Medicine and Health \\ Sciences, University of Gondar, Gondar, \\ Ethiopia
}

Correspondence: Gashaw Dessie Tel +25I 975152796

Email dessiegashaw@yahoo.com

\begin{abstract}
In response to obesity-associated chronic inflammatory disorders, adipose tissue releases a biologically active peptide known as leptin. Leptin activates the secretion of chemical mediators, which contribute to the pathogenesis of chronic inflammatory disorders, such as rheumatoid arthritis (RA), systemic lupus erythematosus (SLE) and psoriasis. Conversely, adiposity and obesity are the major aggravating risk factors in the pathogenesis of metabolic syndrome (MetS), including type II diabetes mellitus and obesity-associated hypertension. Elevated level of leptin in obesity-associated hypertension causes an increase in the production of aldosterone, which also results in elevation of arterial blood pressure. Hyperleptinemia is associated with the progress of the atherosclerosis through secretion of pro-inflammatory cytokines, like interleukin 6 (IL-6), tumor necrosis factor $\alpha$ (TNF- $\alpha$ ), IL17, and other cytokines to promote inflammation. The release of those cytokines leads to chronic inflammatory disorders and obesity-associated MetS. Thus, the aberrant leptin level in both MetS and chronic inflammatory disorders also leads to the complication of cardiovascular diseases (CVD). Therapeutic target of leptin regarding its pro-inflammatory effect and dysregulated sympathetic nervous system activity may prevent further cardiovascular complication. This review mainly assesses the mechanism of leptin on the pathogenesis and further cardiovascular risk complication of chronic inflammatory disorders.
\end{abstract}

Keywords: leptin, chronic inflammatory disorders, cardiovascular

\section{Introduction}

Adipose tissue is the major organ to produce and release leptin. ${ }^{1}$ Leptin was discovered on animal models by Friedman in $1994 .^{2}$ At the time of discovery, treatment of obesity was hopeful on this active adipokine molecule. However, hyperleptinemia was seen in obese individuals after it was found. ${ }^{3}$ Two years after its discovery, low energy signal transmission effect of the central nervous system was identified as its first physiological function. ${ }^{4}$ Neurons found in the ventral tegmental area of midbrain in the hypothalamus express leptin receptors. ${ }^{5}$ Energy homeostasis in the peripheral nervous system is regulated by highly complex interaction of neurons and leptin. ${ }^{6}$ It can be maintained through interaction of leptin signaling pathways with neuropeptide Y neurons. ${ }^{7}$ Leptin regulates the satiety, energy expenditure, inflammation, endothelial cells function, blood pressure, and insulin secretion. ${ }^{8}$ It is proportional to the mass of adipose tissue. ${ }^{9}$ Impairment of adipose tissue results in the release of effector adipokines, including leptin and resistin $^{10}$ (Figure 1). The signaling pathways of leptin can be impaired due to an increase in body mass. ${ }^{11}$ Thus, fat storage and energy homeostasis in adipose tissue could 


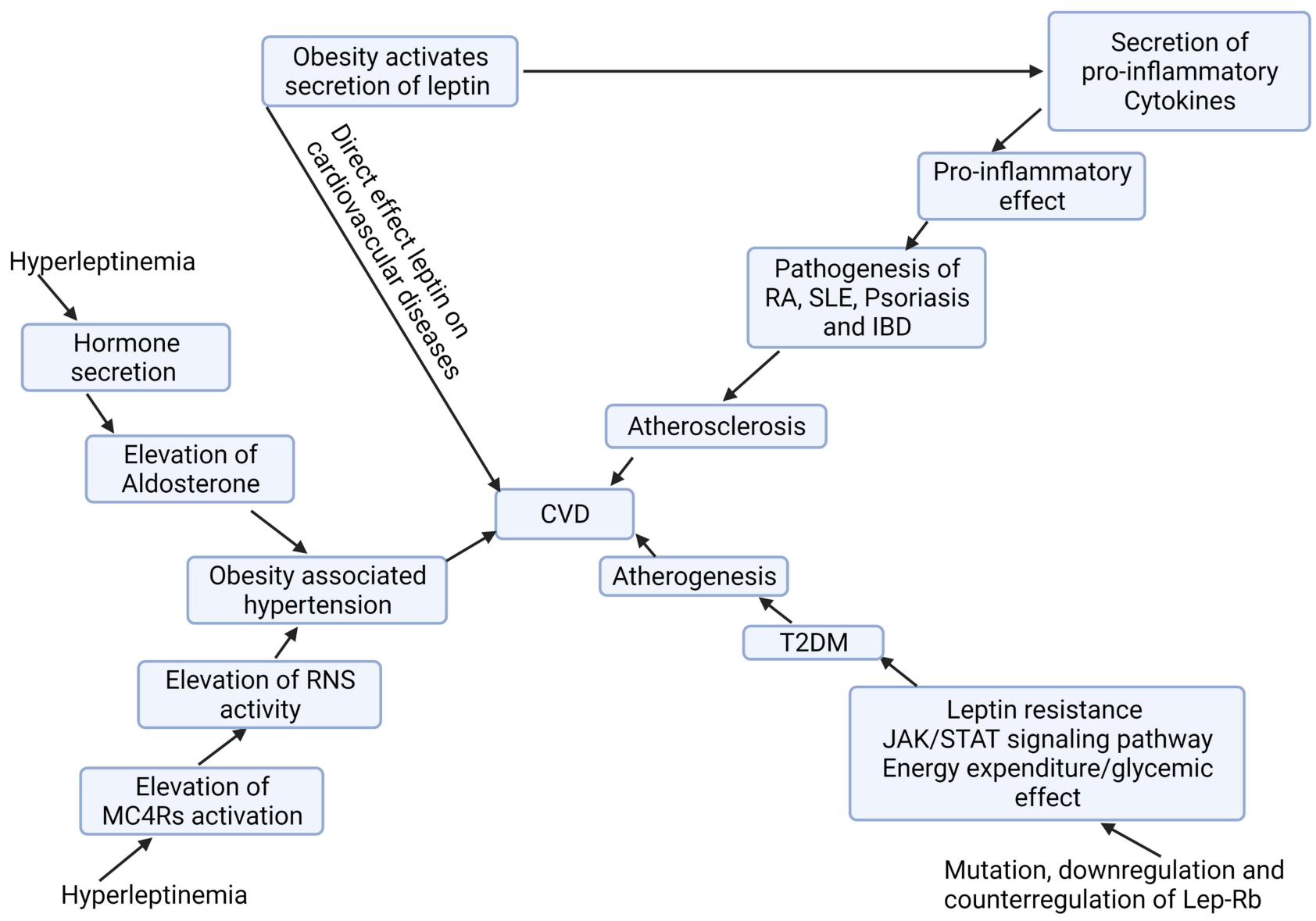

Figure I Leptin for progression of atherosclerosis in T2DM. The synthesis of leptin is associated with atherogenic effect because leptin receptors are found on endothelial cells. Thus, its elevation in obese individuals causes endothelial dysfunction. In this regard, obesity and secretion of leptin is a characteristic feature of T2DM. IL-6 secreted from endothelial cells activate Janus kinase/activators of transcription (JAKs) after it binds to the cytoplasmic domain of gp 30 within macrophage, followed by the phosphorylation of transmembrane tyrosine receptor motifs, such as Tyr905, Tyr8I4, Tyr767, Tyr705 and Tyr915. This leads to increase expression of pro-inflammatory genes through STAT3, which aggravates inflammation and atherosclerosis in T2DM.

Abbreviations: CVD, cardiovascular disease; IL-6, Interleukin-6; JAK/STAT, Janus kinase/ activators of transcription; STAT3, activators of transcription-3; T2DM, type II diabetes mellitus.

be impaired due to the effect of obesity-associated inflammation. ${ }^{10}$ Fatel et $^{12}$ in 2018 mentioned leptin as a pro-inflammatory adipokine because it induces the activation and secretion of the pro-inflammatory cytokines, including tumor necrosis factor- $\alpha$ (TNF- $\alpha$ ), lipopolysaccharide, and interleukin (IL-1). In contrast, the inflammatory cytokines induce the generation and secretion of leptin to promote chronic inflammation. ${ }^{12}$ The pro-inflammatory stimuli, IL-1, TNF- $\alpha$, and lipopolysaccharide lead to upregulation of expression of leptin messenger RNA (mRNA) to aggravate inflammation. ${ }^{13}$ Chronic inflammation may provoke leptin resistance through interruption of its receptor signaling cascade, which in turn leads to hyperleptinemia and obesity. ${ }^{14}$

Leptin is involved in the pathogenesis of various obesity-related inflammatory disorders, such as psoriasis, systemic sclerosis, diabetes, and hypertension. ${ }^{15}$ Psoriasis is an inflammatory skin disease, which is mainly associated with pro-inflammatory cytokines, including IL-6, interleukin 17 (IL-17), interferon-gamma (IFN- $\gamma$ ), and TNF- $\alpha{ }^{16}$ Obesity is an attributable risk factor for the complication of psoriasis. ${ }^{17}$ The autoimmune inflammatory disorders, including systemic lupus erythematosus (SLE) induce the release of leptin to modulate the immune system ${ }^{18}$ that in turn leads to chronic inflammation. ${ }^{19}$ Although there are contradictory data, the majority of studies mentioned elevated level of leptin in SLE patients. ${ }^{20}$ Rheumatoid arthritis (RA) is another chronic autoimmune inflammatory disorder, which leads to the synthesis both of leptin and

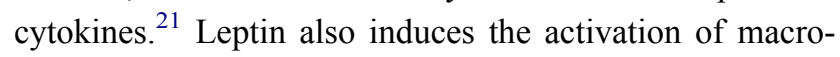
phage, regulatory T-cells and Th17 cells to release proinflammatory cytokines like interleukin 6 (IL-6), TNF- $\alpha$, (IL-17), and other cytokines to promote inflammation. ${ }^{22}$ The binding of leptin to its receptors induces an increase in arterial blood pressure ${ }^{23}$ because obesity-related 
inflammation causes an impairment in leptin sympathetic activity that control the renin-angiotensin system. ${ }^{23}$ The sensitizing effect of leptin on upregulation of the reninangiotensin system increases the risk of hypertension in obese individuals. $^{23}$ In addition to maintaining body weight, leptin is also involved in carbohydrate metabolism $^{24}$ and strengthening sensitivity of insulin in type I diabetes mellitus. ${ }^{25}$ The expression of leptin receptor isoform, Lep-Rb in the peripheral tissue enhances the pathogenesis of various diseases, including immune dysregulation and type II diabetes. ${ }^{26}$

Recently, leptin has gained the insight of the scientific community due to its association with obesity, cardiovascular risk, and insulin resistance. ${ }^{27}$ Evidence has suggested that obesity aggravates the development of chronic inflammation, which in turn leads to metabolic syndrome (MetS). ${ }^{28}$ Characteristic features of MetS, such as hypertension, atherosclerosis, insulin resistance and obesity are correlated with elevated levels of leptin. ${ }^{29}$ Studies revealed that obese individuals with hyperleptinemia are more likely to develop insulin resistance, type II diabetes mellitus, degenerative disease and cardiovascular complications. ${ }^{13,30}$ Studies revealed that insulin sensitivity became decreased in pre-diabetes because of a higher level of leptin. ${ }^{31}$ The development of these chronic diseases are associated with obesityassociated complications. ${ }^{32}$ In contrast, hypertension is one of the obesity-associated MetS, which is caused by an abnormal secretion of leptin. ${ }^{33}$ Increased levels of IL-6, TNF- $\alpha$ and leptin results in dysfunctional epithelial cells, proliferation of smooth muscle cells, and migration of macrophages toward the damaged endothelial cells, which also leads to the development of the cardiovascular risk factors, such as atherosclerosis and hypertension. ${ }^{34}$ Even if contradictory data has been shown in vascular diseases, ${ }^{35}$ hyperleptinemia is the adverse effect of cardiovascular complications such as stroke, heart failure, and acute myocardial infarction. ${ }^{36}$ Although scientific evidence had argument on leptin effect in coronary artery disease, it has a correlation with intimamedia thickness and calcification of coronary artery among type II diabetes mellitus patients. ${ }^{37}$ Coronary artery disease (CAD) is associated with increased synthesis of the perivascular adipose tissue derived leptin and its atherogenic effect. Consequently, the therapeutic target of this active adipokine molecule is recommended to treat obesity-associated cardiovascular complications. ${ }^{38}$ Hyperleptinemia is associated with the progress of atherosclerosis. Thus, the therapeutic target of leptin may decrease the complication of cardiovascular diseases. ${ }^{39}$ Generally, hyperleptinemia acts as a major risk factor for the complication of cardiovascular disease (CVD) in addition to other traditional risk factors ${ }^{40}$ (Figure 1). This review article evaluates the obesity-associated chronic inflammatory diseases and correlates the effect of these disorders with cardiovascular complications. It focuses on the pro-inflammatory effect of leptin in various chronic inflammatory disorders and obesity-associated MetS.

\section{Effect of Leptin in the Pathogenesis of Rheumatoid Arthritis}

According to a clinical and epidemiological global study in 2010, the prevalence of rheumatoid arthritis (RA) was estimated to be $0.24 \%$ and continues without change from 1990 to $2010 .^{41}$ It is characterized by a highly systemic inflammation, which leads to reduced life expectancy and increased mortality rate. ${ }^{42}$ Obesity-associated inflammation increases the burden of RA. ${ }^{43}$ Evidence argues about unknown plasma levels of leptin and its undefined effect in RA patients compared to healthy controls. ${ }^{44}$ However, as early as 2006, a marked elevation of plasma leptin level was detected in RA patients. ${ }^{45}$ Recently, in 2018 , de Souza Fatel et al ${ }^{46}$ tried to confirm the association of RA and leptin. Researchers have various insights about leptin and disease activity in RA. ${ }^{47}$ Studies showed that higher disease activity of RA is associated with hyperleptinemia. ${ }^{48}$ In patients with RA undergoing anti-TNF therapy due to disease severity, there was a strong positive correlation between body mass index of the patient and serum levels of leptin. ${ }^{49} \mathrm{~A}$ recent 12-month multicenter study done in 2020 revealed that the ratio of leptin/fat was elevated in RA patients treated with tocilizumab. ${ }^{50}$ However, the alteration of serum leptin level was not evaluated in their study. It was also the case for RA patients undergoing intravenous therapy with the anti-IL-6 receptortocilizumab. ${ }^{51}$ Moreover, a significant reduction of leptin levels was observed following one single intravenous infusion of the anti-IL-6 receptor tocilizumab. ${ }^{51}$ However, there was no a statistically significant differences in allele frequencies of leptin gene polymorphisms (LEP rs2167270) between RA patients and controls. ${ }^{52}$ A brief report done in Mexico in 2015 suggested the presence of linear association of leptin with disease activity of RA. Skalska and Kontny, ${ }^{53}$ in their 2016 study, clearly describe leptin as a risk factorfor the development of RA.

De Souza Fatel et al revealed that leptin has a proinflammatory effect in the development of RA by activating the secretion of effector cytokines. ${ }^{46}$ Macrophages play a significant role in the development of RA. ${ }^{54}$ 
Leptin activated macrophage induces the release of IL-6 and TNF- $\alpha^{55}$ (Figure 2). In vitro, the chemotactic activity of macrophage is associated with induction of leptin. ${ }^{55}$ In autoimmune diseases, deregulated immune response of cells are affected by alteration of metabolic process within these cells ${ }^{55}$ because leptin binds to its long isoform receptor $(\mathrm{Ob}-\mathrm{RB})$ to induce its biological and physiological effect through JAK/STAT signaling pathway. JAK/ STAT signal transduction is caused by the involvement of Janus kinase 2 ( $J A K 2$ ), activators of transcription (STAT) and transducers found on longer receptor isoform $(\mathrm{Ob}-\mathrm{Rb}) .{ }^{13}$ In addition to leptin, this signaling pathway requires the interaction between complex molecules, including node-like receptor pyrin domain-containing protein 3 (NLRP3), micro RNA-98 (miR-98), caveolin-1 (CAV-1-NR2B) and IL-33. ${ }^{56} \mathrm{JAKs}$ are a group of tyrosine kinases, which bind to type I and II tyrosine receptor family, ${ }^{57}$ whereas STATs are factors that are phosphorylated by cytokines activated tyrosine motifs. ${ }^{58}$ Leptinreceptor interaction begins after leptin binds to $\mathrm{Ob}-\mathrm{Rb}$, extracellular domain, later Jak2 tyrosine kinase become activated. ${ }^{59}$ This in turn causes auto-phosphorylation of Jak2 and intracellular Tyr1138, Tyr1077, and Tyr985 motifs. $^{13}$ Physically associated receptor-JAK complex activate phosphorylation of STATs, including STAT1, STAT2, STAT3, and other transcriptional signaling molecules. ${ }^{60}$ In addition, phosphorylated Tyr1138 induces the phosphorylation of STAT3, which is exported to the nucleus for targeted gene transcriptional process. ${ }^{59}$ This signaling cascade within macrophage induces synthesis of pro-inflammatory cytokines, including IL-6 and TNF- $\alpha^{61}$ (Figure 2). Then, IL-6 and TNF- $\alpha$ are released from macrophage to promote inflammation and contribute to the pathogenesis of RA. ${ }^{62}$ Although effective anti-arthritis therapies are designed from these first-class adipokines, drugs from leptin and other adipokines may also be formulated. $^{63}$ Chronic inflammation resulted from JAK/ STAT signaling may be altered with a therapeutic drug (Jakinibs) in rheumatoid arthritis patients. ${ }^{56}$ In addition, leptin induces macrophage chemotaxis, synthesis and

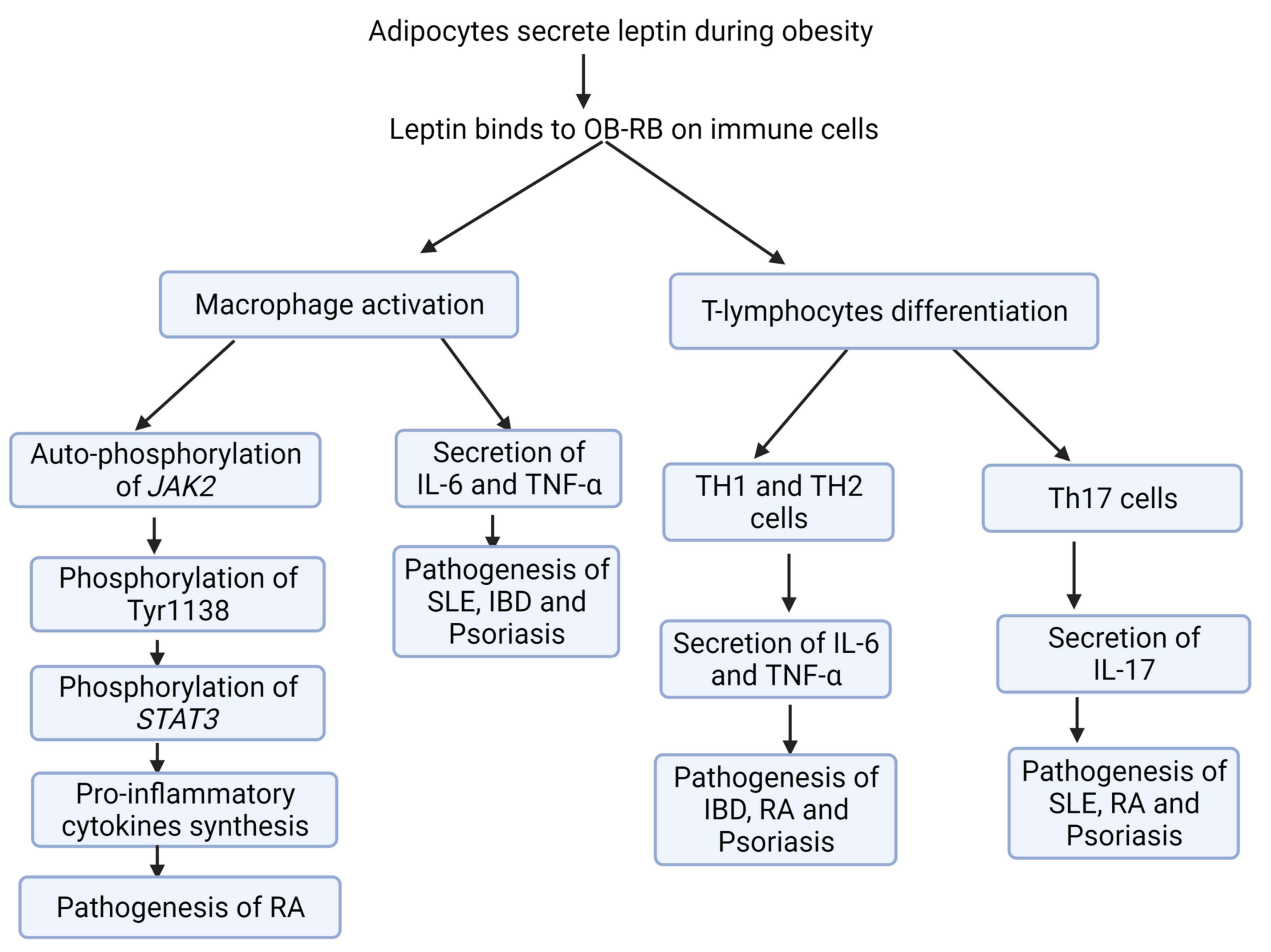

Figure 2 Cumulative effect of leptin on both chronic inflammatory disorders and further cardiovascular complication. The homeostatic role of adipose tissue impaired due to obesity-associated inflammation. The impairment of adipose tissue results in the release of effector adipokines, including leptin. The adipokines secreted by adipose tissue involve in obesity related inflammatory disorders, such as psoriasis, SLE and RA by activating of secretion of various cytokines. Conversely, obesity induced inflammation causes an impairment in sympathetic activity that controls the renin-angiotensin system through secretion of aldosterone, which results in elevation in water and salt retention and leads to obesity-associated hypertension. The reduced physiological activity of leptin on adipose tissue to oxidize stored fat leads to a phenomenon known as leptin resistance. In this regard, leptin resistance occurs in diabetic and obese subjects. Adiposity and obesity are risk factors for the occurrence of metabolic syndrome, such as T2DM and hypertension. In addition to this, RA, psoriasis and SLE are developed due to adiposity and obesity, which in turn leads to cardiovascular complications. Abbreviations: CVD, cardiovascular disease; IBD, inflammatory bowel disease; JAK/STAT, Janus kinase/activators of transcription; Lep-Rb, leptin receptor isoform-b; RA, rheumatoid arthritis; MC4Rs, melanocortin-4 receptors; SLE, systemic lupus erythematosus; SNS, sympathetic nervous system; T2DM, type II diabetes mellitus. 
release of pro-inflammatory cytokine, IL-12. ${ }^{61}$ Similarly, leptin activated macrophage induces synthesis of IL-18 to mediate T-helper 1 immune response. ${ }^{64}$ Secreted IL-18 and IL-12 enable differentiation of Th1 phenotype from T-helper cells and activate synthesis of interferon- $\gamma$ (IFN$\gamma)$ and IL-2. Converely, Th1 cells synthesize leptin and induce the release of IL-18, IL-12, IL- 6 and TNF- $\alpha$ by stimulating macrophage. ${ }^{65}$ The expression of glycoprotein (CD38), adhesion molecules, CD25, and CD69 also increased within activated macrophage. ${ }^{61}$

In contrast, leptin contributes to the progression of RA by downregulating regulatory T-cell activity $\left(\mathrm{CD} 4^{+} \mathrm{CD} 25^{\text {high }}\right)$ and upregulating the activity of T-helper $1\left(\mathrm{~T}_{\mathrm{H}} 1\right)$ cells. ${ }^{66}$ Diminished level of Treg cells seen in an opposite effect to the level of leptin and BMI in obese individuals. ${ }^{55}$ The experiment done in leptin-deficient mice showed the anti-inflammatory potential of leptin by inhibiting inflammatory agents. However, it elevates systemic inflammation in RA through $\mathrm{T}_{\mathrm{H}} 1$-mediated immune response. ${ }^{67}$ T-helper $1\left(\mathrm{~T}_{\mathrm{H}} 1\right)$ cells promote inflammation in different autoimmune disorders, including RA. ${ }^{68}$ The elevated ratio of both regulatory T-cell and Th17 cells (Th17/Treg) and Th1/Th2 promote the pathogenesis of $\mathrm{RA}^{69}$ (Figure 2). Even if there is no well-defined association among adipokines and RA, leptin is one metabolic risk factor. ${ }^{70}$ In addition, elevation in leptin/adiponectin ratio and positive association of leptin with homeostasis model assessment of insulin resistance (HOMA-IR) indicates magnitude of atherosclerosis development and plaque formation. ${ }^{70}$ Therefore, leptin plays a significant role in the pathogenesis of RA and risk of cardiovascular complication.

\section{Hyperleptinemia and Cardiovascular Risk in Systemic Lupus Erythematosus}

Systemic lupus erythematosus (SLE) is chronic autoimmune inflammatory disease characterized by inflammation of connective tissue. ${ }^{71}$ Versini et $\mathrm{al}^{72}$ et al, in 2017, mentioned the availability of inadequate data regarding the association between obesity and SLE through their crosssectional study. Although studies argue regarding the association of leptin with SLE, an increase in serum leptin concentration may elevate systemic inflammation in SLE. ${ }^{73}$ Even though contradictory data are available, findings showed that the level of leptin increases in SLE. $^{27,66,73}$ In contrast to this, the other meta-analysis done on leptin and SLE revealed that diminished level of leptin is shown in SLE. ${ }^{74}$ Alternatively, studies done in Egypt in 2018 confirmed the presence of higher level of serum leptin among SLE patients. ${ }^{19}$ Elevated level of leptin is correlated with MetS and obesity, which act as an exposure risk factors for chronic autoimmune diseases, including SLE. ${ }^{74}$ In the pathogenesis of SLE, the immune system is affected by leptin, which serves as a pro-inflammatory cytokine. ${ }^{75}$ In this regard, macrophages synthesize TNF- $\alpha$ due to the stimulatory effect of leptin. ${ }^{76}$ Therefore, SLE patients with CVD show an elevated level of IL-1 and TNF- $\alpha .{ }^{77}$ At the onset of inflammation, leptin increases the synthesis of inflammatory mediators, including IL-6 and TNF- $\alpha{ }^{78}$

Leptin contributes to the pathogenesis of SLE by activating the synthesis of auto-antibody production and dysregulation of the immune system. ${ }^{79}$ Although the pathogenesis of SLE is still undefined, the circulating auto-antibodies activate secretion of inflammatory cytokines, which in turn contribute to the progress of SLE. ${ }^{80}$ Beyond leptin's significant enrollment, both auto-antibodies and $\mathrm{CD}^{+} \mathrm{T}$-cells play another significant role in the pathogenesis of SLE. ${ }^{18}$ The abnormal activation of $\mathrm{CD}^{+}$ T-cells and mediated inflammatory responses are seen in SLE patients. ${ }^{80}$ Immune dysregulation associated with leptin is due to an increase in differentiation of Th17 cells, ${ }^{18}$ which in turn lead to tissue damage in autoimmune disorders, including SLE. ${ }^{79}$ The effector cell, Th17 induces inflammation by the activating secretion of IL-17 which also enhances tissue damage and inflammation in psoriasis, SLE, and $\mathrm{RA}^{81}$ (Figure 2).

\section{Role of Leptin in the Pathogenesis of Psoriasis}

Psoriasis is a chronic inflammatory disease in joints, nails and skin due to immune modulation, environmental, and genetic variation. ${ }^{82}$ The World Health Organization describes it as a global health burden, and the prevalence of disease is expected to be $2 \%$ in Western countries. ${ }^{83}$ The complication of psoriasis is related to the effects both of MetS and obesity. ${ }^{82}$ Profumo et $\mathrm{al}^{84}$ in 2012 mentioned the development of obesity in psoriatic patients. Obesity has an association with inflammatory skin cells by modulating their activity. ${ }^{85}$ It also induces chronic inflammation by activating the secretion of cytokines and leptin. ${ }^{86}$ The release of adipokines contribute to a chronic cutaneous inflammation in psoriasis. ${ }^{87}$ Leptin plays its own role in the promotion of psoriasis through secretion of proinflammatory mediators, which are recruited to cutaneous 
lesions. ${ }^{88}$ Although cutaneous psoriasis patients at moderateto-severe stages of the disease treated with anti-TNF biologics, leptin correlated with MetS features and inflammation. In this regard, in these patients with moderate-to-severe psoriasis, leptin concentration is correlated with $\mathrm{C}$-reactive protein and with systolic and diastolic blood pressure before the onset of the anti-TNF-adalimumab therapy. ${ }^{89}$ A negative correlation with insulin sensitivity was also found. ${ }^{89}$ Although clarification on anti-inflammatory and pro-inflammatory effect of psoriasis is challenging, the expression of anti-inflammatory cytokines resolve Th2 and Th1/Th17 unbalanced proportion in psoriasis. ${ }^{16}$ However, studies done in mice showed that leptin induces and activates the differentiation of T-lymphocytes into T-helper-1 lymphocytes (Th1 lymphocytes) to release proinflammatory cytokines, including TNF- $\alpha$, IL-6 and IL- $8^{90}$ (Figure 2). Researchers have confirmed that leptin increases the genetic expression of IL- 6 both in humans and rats. ${ }^{91}$

Regard to psoriasis pathogenesis, Th1-cells are responsible for the synthesis of TNF- $\alpha$, IFN- $\gamma$ and IL-2. ${ }^{16}$ Similarly, Th17 cell becomes differentiated due to stimulatory effect of IL-6 and this cell also induces the release of IL-17, IL-6, IL22 and IL-2 $1^{16}$ (Figure 2). The systemic inflammation is due to a network of cytokines activation such as IL-2, TNF- $\alpha$, IFN- $\gamma$, IL-6, IL-17, IL-21, IL-22 and others. ${ }^{16}$ The secreted cytokines cascade promote the development of accelerated atherosclerosis in psoriasis patients. ${ }^{89}$ The IL-17 deficient mice showed diminished level atherosclerotic plaque formation, hence IL-17 lymphocytes may be involved in atherosclerosis development. ${ }^{83}$ From a common perspective, inflammation mediated atherosclerosis has a common process similar to CVD. ${ }^{83}$ Similarly, leptin induces the secretion of pro-inflammatory cytokines like TNF- $\alpha$ and IL- 6 from macrophages and inhibits secretion of Th2 cytokines. ${ }^{92}$ In this context, the pro-inflammatory effect of TNF- $\alpha$ has been activated, ${ }^{89}$ whereas the anti-inflammatory effect of Th2 cytokines will be downregulated. ${ }^{92}$ Studies showed that Th2-produced IL-10 may assist psoriasis therapy because it diminishes synthesis of chemokines and pro-inflammatory cytokines from macrophage. ${ }^{93}$ Inflammation enhances pathophysiology of psoriasis, which in turn leads to the risk of cardiovascular complications. ${ }^{83}$

\section{Leptin and Intestinal Inflammation in Inflammatory Bowel Disease}

Inflammatory bowel disease (IBD) is a chronic inflammation of the digestive tract that includes ulcerative colitis ${ }^{88}$ and Crohn's disease. ${ }^{76,94}$ The incidence of IBD is higher in developed countries, but its prevalence is lower in developing countries compared to the former one. ${ }^{94}$ Intestinal microbiome difference, smoking habits, lifestyle modification, and a variation on dietary content are some of the factors, which contribute to variation in the prevalence of IBD. Genetic, environmental factor, abnormality in immune response, and intestinal microbiome contribute to the development of IBD. ${ }^{94}$ Studies describe IBD as an inflammatory disorder, which is characterized by an increase in the level of pro-inflammatory cytokines, including, TNF- $\alpha$, IL-6, and IL-1 ${ }^{94}$ (Figure 2). Researchers have revealed that the pathogenesis of IBD is associated with activation of nuclear factor- $\kappa \mathrm{B}(\mathrm{NF}-\kappa \mathrm{B})$, which enhances the genetic expression of pro-inflammatory cytokines. ${ }^{95}$ Binding of leptin to its receptors found on immune cells of lamina propria and small intestine enterocytes induce NF- $\kappa \mathrm{B}$ activation, ${ }^{96}$ which in turn leads to villi cell apoptosis phenomena within intestinal mucosa. Migration of macrophage toward dead cells enhance and release pro-inflammatory cytokines, including IL-6, IL-1, and IL-12. ${ }^{97}$ Neutrophils migrate toward the inflamed intestine ${ }^{98}$ and synthesize or secrete leptin, but its proportion is not comparable to adipose tissue. $^{99}$ The cytokines secreted from macrophage are due to the stimulatory effect of leptin, especially in patients with Crohn's disease (CD). ${ }^{96}$ In contrast, proinflammatory cytokines, including TNF- $\alpha$, IL-6, and IL-1 induce an elevated activity of leptin in inflamed tissue. ${ }^{100}$ Thus, neutrophils play a vital role in the pathogenesis of IBD by mediating intestinal inflammation. ${ }^{98}$ During intestinal microbiome disturbance, adipocytes also involve in innate immune response through generation of leptin. ${ }^{101}$ In addition, characteristic systemic inflammation shown in IBD is associated with elevated $\mathrm{CD}^{+}$cells polarization to Th1 cells, which in turn lead to release of pro-inflammatory cytokines $^{97}$ (Figure 2).

\section{Leptin Involved in the Progression of Atherosclerosis in Type II Diabetes Mellitus}

In the US, $34 \%$ of the population are challenged with complication of type II diabetes mellitus (T2DM). ${ }^{102}$ This is because both obesity and T2DM are highly associated with each other. ${ }^{102}$ Obesity is the major risk factor for the pathogenesis of diabetes mellitus. ${ }^{103}$ Type II diabetes mellitus is characterized by obesity and secretion of leptin. ${ }^{104}$ The production of leptin is related with atherogenic effect, ${ }^{104}$ because 
its elevation in obese individuals causes endothelial dysfunction $^{103}$ (Figure 3). Leptin binds to its receptors on neutrophils ${ }^{105}$ and activates the chemotaxis and phagocytosis process. ${ }^{106}$ The effect of leptin on the generation of reactive oxygen species is still undefined, ${ }^{105}$ but it causes the migration of leukocytes toward injured tissue. ${ }^{106}$ At the onset of inflammation, leptin increases the synthesis of pro-inflammatory mediators like IL- 6 and TNF- $\alpha{ }^{78}$ IL- 6 and TNF- $\alpha$ are synthesized from macrophage within endothelium and contribute to the atherogenic process. ${ }^{107}$ In addition to macrophage, different types of cells are responsible for secretion of IL-6, including endothelial cells, adipocytes, and skeletal muscle cells. ${ }^{108}$ In contrast to pro-inflammatory effect, leptin activates synthesis of anti-inflammatory cytokines, including IL-4 and IL-10 from different types of immune cells. ${ }^{65}$ However, in T2DM, the vascular complication promoted by the active pro-inflammatory mediator, IL-6 through JAK/ STAT signal transduction pathway. ${ }^{109}$ The interaction of this cytokine with its receptor induce activation of JAK/STAT signaling pathway. ${ }^{60}$ The transphosphorylation of JAK and
STATs is related with stimulation of receptors. ${ }^{57}$ Janus kinase/activators of transcription (JAK) activation is caused by the binding of IL- 6 to the cytoplasmic domain of gp130 followed by auto-phosphorylation of JAK and phosphorylation of transmembrane tyrosine receptor motifs, including Tyr905, Tyr814, Tyr767 and Tyr915. ${ }^{99,110}$ In addition, phosphorylation of both ser727 and Tyr705 residues of Ob-RB also occurred within macrophage. ${ }^{111}$ Mitogen activated protein kinases (MAPKs) are responsible for serine 727-phosphorylation of STAT3 and STAT1, which act as linkage sites for MAPK and STATs. ${ }^{112}$ Activators of transcription-3 (STAT3) are the major activation transcription factor for leptin signaling cascade, which requires phosphorylation of Tyr705. ${ }^{109}$ In addition to Tyr705, extracellular regulated kinase (ERK)-activated phosphorylated ser727 also mediates STAT3 stimulation during leptin signaling cascade. ${ }^{111}$ Then, STAT3 dimerizes, phosphorylates and translocates to the nucleus to activate pro-inflammatory gene expression. ${ }^{109}$ The translocated STAT binds to gamma-activated sites ${ }^{113}$ and interferon-stimulated response elements (ISREs) which

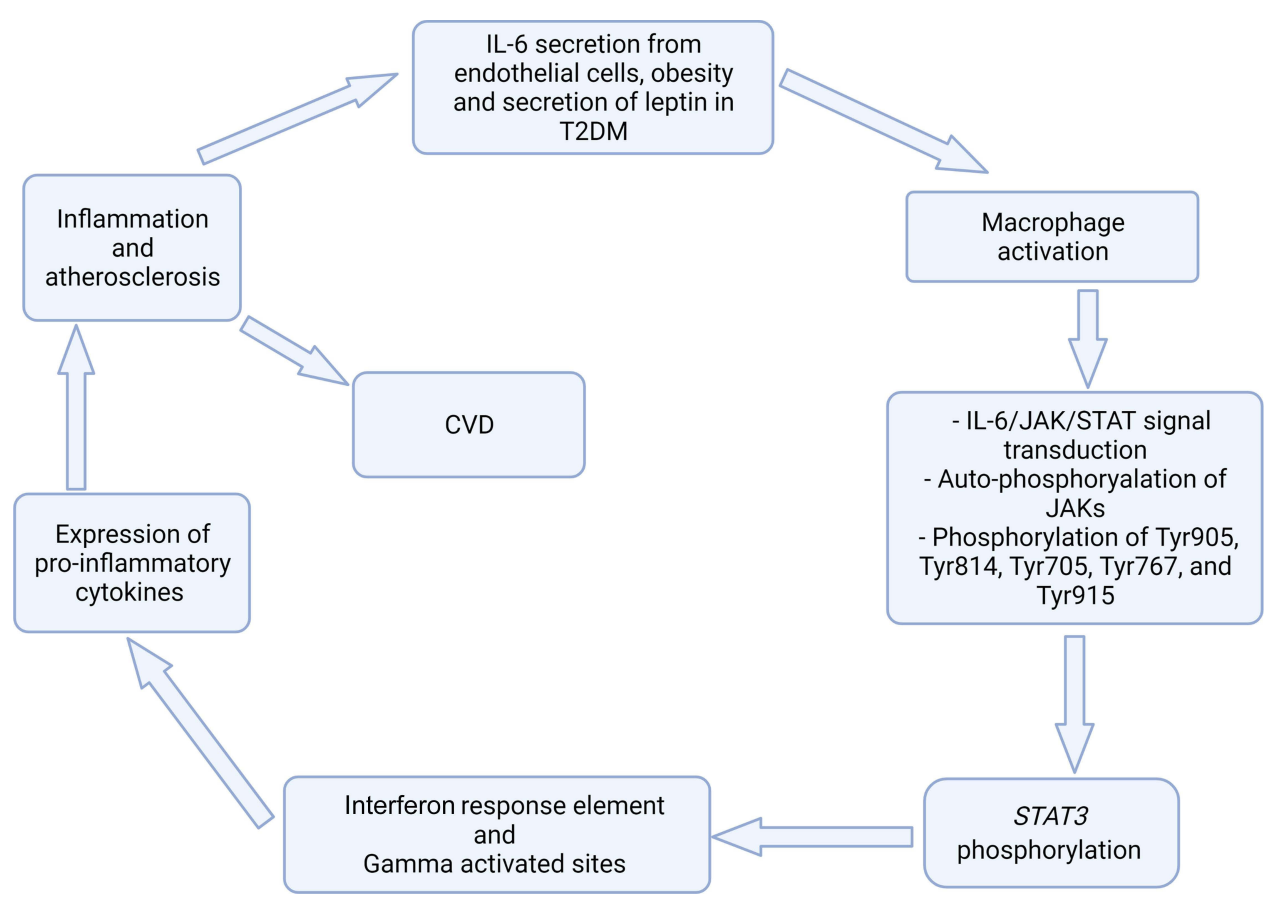

Figure 3 The impact of leptin on the pathogenesis of chronic autoimmune inflammatory disorders. Leptin binds to its long isoform receptor (Ob-RB) on macrophage to induce its biological and physiological effect through a JAK/STAT signaling pathway. This signaling cascade within macrophage induces the synthesis of pro-inflammatory cytokines, including IL- 6 and TNF- $\alpha$. The synthesis and release of IL- 6 and TNF- $\alpha$ also involves the pathogenesis of RA. Similarly, IBD is one of inflammatory disorders which is characterized by elevation in the level of pro-inflammatory cytokines, including TNF- $\alpha$, IL- 6 and IL-I that leads to the development of diseases. In contrast, the immune dysregulation related to leptin is due to elevated differentiation of Thl7 cell, which in turn leads to tissue damage in autoimmune inflammatory disorders, including, SLE, psoriasis, and RA. The effector cell, ThI7 induces inflammation by the activating secretion of IL-I7 which also enhance tissue damage and inflammation in SLE. In the pathogenesis of psoriasis, studies done in mice showed that leptin induces and activates the differentiation of T-lymphocytes to T-helper-I lymphocytes (ThI lymphocytes) to release pro-inflammatory mediators, including TNF- $\alpha$, IL-6 and IL-8.

Abbreviations: IBD, inflammatory bowel disease; IL-6, interleukin-6; IL-I7, interleukin- I7; JAK/STAT, Janus kinase/activators of transcription; RA, rheumatoid arthritis; SLE, systemic lupus erythematosus; ThI and 2 cells, T-helper-I and 2- lymphocytes; ThI7 cells, T-helper-17 cells; TNF- $\alpha$, tumor necrosis factor-alpha. 
are involved in the signaling cascade of IFN and acute phase response $^{109}$ (Figure 3).

In contrast, the lower level of leptin seen both in rodents and humans indicates the presence of normal metabolic activity of cells. ${ }^{114}$ The higher insulin concentration in the circulation leads to the deposition of fat in adipose tissue in the form of triglyceride. ${ }^{115,116}$ In response to accumulated fat, leptin will be secreted by adipose tissue to oxidize it. But, the physiological activity of leptin does not act on adipose tissue to oxidize stored fat, which leads to a phenomenon called leptin resistance. ${ }^{114}$ The demonstration done on rats showed that leptin resistance may be caused by downregulation of genetic expression of Lep-Rb in the hypothalamus. In addition to this, its signal transduction pathway can be inhibited through suppressor of cytokine signaling-3 (SOCS3) having counter regulatory effect. ${ }^{117}$ Studies done on mice confirm that obesity was inhibited by avoiding SOCS3 and protein tyrosine phosphatase 1B in the pro-opiomelanocortin (POMC) neurons. ${ }^{118}$ Elevation of counter regulatory signaling pathways and overexpression of leptin receptor cause inhibition of leptin signaling cascade, which in turn leads to leptin resistance. Therefore, hypothalamus promotes the sensitivity of leptin through upregulation of STAT3, JAK2 and diminished genetic expression of SOCS3. ${ }^{119}$ In addition to its receptor aberration, a defect in transportation of leptin also contributes to leptin resistance. ${ }^{120}$ The expression of leptin receptor isoform (Lep- $\mathrm{Rb})$ in the brain activates transportation of leptin to undergo its biological and physiological effect on hypothalamus. However, the blood-brain barrier inhibits transportation of leptin. ${ }^{121}$

Diminished response to biological and physiological action of leptin commonly occurs in obese individuals. ${ }^{122}$ The observational study done by Kennedy et al ${ }^{123}$ in 2016 explained that elevated level of leptin was seen in hyperglycemia condition. In the hypothalamus, the JAK-STAT signaling pathway is induced through interaction of Lep-Rb and leptin, which leads to the biological effect of leptin action. ${ }^{124}$ The glycolipid metabolism is regulated by leptin binding to its long isoform receptor, Lep-Rb which is found in the liver and hypothalamus. ${ }^{125}$ Lep-Rb/STAT3 signaling controls glycemic index, hence leptin regulates STAT3 and phosphatidyl inositol-3 kinase (PI3K) activity. ${ }^{126}$ Glucose reduction activity of leptin through energy expenditure enhances insulin sensitivity effect. ${ }^{127}$ However, in animal models, the mutated leptin receptor gene may be associated with leptin action, T2DM pathogenesis, and obesity ${ }^{124}$ (Figure 1). Leptin resistance occurs both in diabetes and obese subjects. ${ }^{128} \mathrm{An}$ investigation done on an animal model showed that leptin replacement therapy decreased hepatic gluconeogenesis and hyperglycemia condition. ${ }^{129}$ Leptin therapy is not an adequate alternative method due to unresponsiveness to its physiological action. Therefore, additional desensitizing molecules should be combined with leptin to strengthen its anti-obesity activity. ${ }^{122}$ If the anti-obesity activity of leptin therapy is enhanced, the stored fat will be oxidized, as well as insulin sensitivity elevated. Hence, the pathogenesis of diabetes might be decreased.

\section{Leptin in the Pathogenesis of Obesity-associated Hypertension}

Globally, the obesity-associated hypertension increases at a higher rate. ${ }^{130}$ Several researchers confirmed that leptin leads to obesity related to hypertension. ${ }^{131}$ A recent investigation tried to evaluate blood pressure in lipodystrophy patients through administration of leptin. Although they identified elevated level of leptin, patients did not show a significant variation as their blood pressure is measured. ${ }^{132}$ However, mutation of leptin and its receptor may cause severe obesity in human beings, but normal or lower arterial pressure and sympathetic tone may be detected. ${ }^{133-135}$ Obesity is a well-known risk factor for the development of hypertension. ${ }^{136}$ In premenopausal women, obesity induces three-fold elevation for the progression of hypertension. ${ }^{131}$ The abnormal secretion of biologically active peptide, leptin leads to aberration of the appetite regulation, insulin sensitivity, inflammation, and elevation of blood pressure (BP). ${ }^{137}$ A recent investigation revealed that hypertension developed through elevation of the sympathetic nervous activity. ${ }^{138}$ Blood pressure is maintained through interconnected activity of the hormonal factors, such as TNF- $\alpha$, angiotensin, melanocortin, and leptin. ${ }^{130}$ High fat diet intake causes the secretion of effector molecules, such as leptin and TNF- $\alpha$ to induce their sympathetic activity on hypothalamus. ${ }^{130}$ Independent of food consumption, leptin regulates sympathetic activity and BP. ${ }^{139}$ It affects BP by elevating sympathetic nervous system and aldosterone levels. ${ }^{139}$ Protein tyrosine phosphatase 1B (PTP1B) and SOCS3 have negative feedback on the effect of leptin by induction of leptin resistance. As leptin resistance occurred, the biological effect of leptin on sympathetic nervous system (SNS) becomes disrupted, which contributes to arterial hypertension pathogenesis. ${ }^{140}$ Investigations done on rodents and humans revealed that BP becomes elevated as leptin infusion occurred at hypothalamic arcuate nucleus (ARC). On 
contrast, BP and heart rate decreased due to downregulation of leptin receptor in the proopiomelanocortinergic (POMC) neurons. ${ }^{141}$

Leptin activates SNS to induce obesity related to hypertension ${ }^{23}$ because it affects autonomic nervous system in Lep-Rb containing neurons. ${ }^{142}$ In contrast to this, the activity of SNS and BP can be impaired during intravenous administration of leptin in humans. ${ }^{143}$ Sympathetic nervous system and BP are regulated through the activation of melanocortin-4 receptors (MC4Rs) in brain stem nuclei, hence the renal SNS is altered. ${ }^{144}$ The lysis of POMC protein induces the synthesis of $\alpha$-melanocyte-stimulating hormone $(\alpha-\mathrm{MSH})$, which in turn activates MC4Rs. ${ }^{144}$ The sensitization of hypothalamus MC4Rs induces an increase in renal system activity, including elevated sodium retention and secretion of renin, further leading to an increase in BP. ${ }^{144}$ In addition to this, receptors of leptin are mainly expressed in the hypothalamus and are responsible for elevated secretion of aldosterone, which also depends on the level of $\mathrm{Ca} 2+.{ }^{145} \mathrm{Xie}$ and Bollag et $\mathrm{al}^{146}$ in their focused review elaborate that leptin stimulates overproduction of aldosterone. The elevated level of aldosterone also leads to elevate retention of salt and water by the kidney, which results in an increase in $\mathrm{BP}^{146}$ (Figure 1). Consequently, elevated level of leptin among obese individual leads to hypertension through increased production and secretion of aldosterone.

\section{Hyperleptinemia Aggravates Further Cardiovascular Risk Complication}

Globally, cardiovascular diseases (CVD) are a major health burden, which accounts for up to 12.3 and 17.6 million deaths in 1990 and 2016, respectively. ${ }^{147}$ Different types of diseases are categorized under CVD, including coronary artery diseases, ${ }^{148}$ myocardial infarction, heart failure, rheumatic heart diseases, stroke, and congenital heart diseases. ${ }^{149}$ Stroke and coronary artery disease (CAD) are the major factors for the global death burden both in high and low-income countries. ${ }^{150}$ In the USA, 15.4 million people were diagnosed with CAD from 2007 to 2010 whose age was greater than 20 years old. ${ }^{40}$ Researchers are in contention whether leptin has a positive or negative impact on the heart and vascular system. ${ }^{151}$ Perivascular fat has a characteristic of atheroprotective vascular homeostasis and give a mechanical strength for vasculature through release of leptin. However, it loses its biological function during obesity. ${ }^{152,153}$ The expression of leptin has been elevated because of obesity-associated perivascular adipose tissue. ${ }^{154}$ In contrast, investigations done on hypertensive rats showed the expression of perivascular adipose tissue (PVAT)-derived leptin was decreased. ${ }^{155}$ Perivascular-derived leptin leads to vessel stiffness during obesity. ${ }^{153}$ In addition, SNS activity become elevated due to the release of leptin. ${ }^{156}$ In addition to leptin, PVAT activates the release of monocyte chemoattractant protein-1 (MCP-1), IL-8, IL-6, and $\mathrm{TNF}-\alpha$ to promote the development of atherosclerosis through activation of smooth muscle cell migration. ${ }^{157}$ Perivascular-derived leptin activates macrophage migration, expression of adhesion molecule, synthesis of free radicals, secretion of IL- 6 , and TNF- $\alpha .{ }^{158}$ Obesity-associated perivascular adipose tissue activates p38 mitogenactivated protein kinases signaling pathways to induce phenotypic change on vascular smooth muscle cells.

Published scientific conclusions on the effect of leptin on vascular diseases differ. ${ }^{35}$ Several animal studies revealed that the pathogenesis of cardiac hypertrophy is associated with obesity. ${ }^{159}$ Although leptin causes increased ventricular thickness and cardiac mass, its effect on cardiac hypertrophy is still undefined. It may lead to cardiac remodeling through triggering its biological and physiological effect using PI3K, mitogen-activated protein kinase (MAPK) and JAK/STAT3 signaling cascade mechanism. ${ }^{160}$ However, cardiac hypertrophy may develop because of activation of SNS and renin-angiotensin-aldosterone system. ${ }^{161}$ Stangl et $\mathrm{al}^{162}$ in 2000 carried out a demonstration on mice, and they confirmed that infusion of leptin leads to an increase in sympathetic activity of certain organs. Binding of leptin to its receptors induce the activation of SNS. ${ }^{163}$ Receptors of leptin found on vascular cells indicate the potential role of leptin in the function of the vascular system. ${ }^{164}$ Therefore, it has autocrine and paracrine effects on the vascular modulation process. ${ }^{36}$ Investigations done on animal models showed that leptin leads to the development of atherosclerosis and thrombosis, which act as risk factors for $\mathrm{CAD} .^{27}$ Even though animal investigations revealed that it contributes to atherosclerosis development, ${ }^{115}$ findings from clinical investigations as well as experimental animal studies showed leptin's protective effect against atherosclerosis. ${ }^{165,166}$ With regard to this, the synthesis of reactive oxygen species (ROS) increased rapidly after the treatment of leptin. ${ }^{167}$ In addition to CAD, evidence revealed that heart failure is caused by increased genetic expression of leptin and its receptors. ${ }^{168}$ In contrast, 
congestive heart failure causes an elevation in leptin plasma level. ${ }^{167}$ The induction of leptin signal transduction pathway through PI3K, MAPK, JAK2/STAT3 results in biological and physiological response in different tissues, including left ventricular, which is related to left ventricular hypertrophy (LVH). ${ }^{160}$ Moreover, angiotensin II-associated myocardial remodeling may be due to the biological effect of leptin through its signal transduction. ${ }^{160}$ In vitro investigation showed that rodent and human cardiomyocyte hyperplasia were activated by the effect of leptin. ${ }^{169}$

Adiposity and obesity are the major risk factors for the pathogenesis of MetS, such as T2DM and hypertension, which in turn leads to cardiovascular complications, ${ }^{170}$ because abnormality in adipose tissue and obesity induce a chronic inflammation. ${ }^{55}$ Adiponectin/leptin ratio will be diminished during systemic inflammation to induce pathogenesis of various MetS. ${ }^{10}$ In this regard, researchers agree with influence of dysfunctional adipokines on the pathogenesis of MetS. ${ }^{171}$ This is due to a positive correlation between the level of leptin and development of atherosclerosis ${ }^{172}$ (Figure 1). Elevated mass of adipose tissue is characterized by increased secretion of adipokines, which contribute to the pathogenesis of atherosclerosis. ${ }^{35}$ Furthermore, the association between leptin and atherosclerosis is mainly associated with leptin resistance instead of hyperleptinemia. ${ }^{173}$ Leptin resistance occurs in diabetes and obese subjects. ${ }^{128}$ On behalf of the obesity-associated hypertension, elevated level of leptin leads to an increase in the production of aldosterone. Elevated aldosterone level also leads to increased retention of salt and water by the kidney, which results in an increase in blood pressure. ${ }^{146}$

Although it is difficult to clarify the mechanism of development of atherosclerosis, SLE patients may develop atherosclerosis. ${ }^{174}$ This is because of development of atherosclerosis, which may be associated with the deposition of cholesterol ester (CE) in foam cells during endothelial dysfunction. ${ }^{175}$ Concerning the atherosclerosis, a huge cohort study was done in Systemic Lupus International Collaborative Clinics (SLICC) on 1249 patients and 31 of them developed atherosclerosis. ${ }^{174}$ In addition to this cohort study, the population-based research done in Sweden confirmed that higher incidence of CVD was seen in SLE patients. ${ }^{176}$ According to this study, SLE patient's within the age range of 20-39 years have 16 times higher cardiovascular mortality risk than the general population. Similarly, Lewandowski and Kaplan ${ }^{177}$ in 2016 also describe that one third of deaths of SLE patients are due to cardiovascular complications. Therefore, the risk of developing CVD is higher in SLE patients due to the development of atherosclerosis $^{174}$ (Figure 1). In contrast, numerous investigations confirmed that IBD leads to the risk of cardiovascular complication, ${ }^{178}$ which is associated with involvement of leptin in the development of atherosclerosis ${ }^{178}$ (Figure 1). Regarding psoriasis, inflammation promotes pathophysiology of disease, which in turn leads to the risk of cardiovascular complication. ${ }^{83}$ Thus, CVD is one of the comorbidity effects of psoriasis. ${ }^{83}$ Similarly, patients with RA are 1.5 times more likely to develop CVD as compared to the general population. ${ }^{179}$ Adipokines modify the immune system and metabolic activity of cartilage, and bone which results in the occurrence of MetS. ${ }^{170}$

\section{Conclusion}

Leptin induces the activation and release of pro-inflammatory cytokines, including IL-6, TNF- $\alpha$, IL-17 and other cytokines to promote systemic inflammation in RA, SLE and psoriasis. Leptin-activated pro-inflammatory mediators contribute to complication of atherosclerosis in T2DM. Conversely, it induces obesity-associated hypertension through activation of sympathetic nervous system in Lep$\mathrm{Rb}$ containing neurons. It increases the secretion of aldosterone, which in turn causes an increase in arterial blood pressure. Consequently, the development of both MetS and chronic inflammatory disorders leads to the pathogenesis of CVD such as coronary artery disease and stroke. This review strongly suggests that the adverse individual effect of leptin on chronic inflammatory diseases in turn increases the risk of developing CVD. Therapeutic target of leptin regarding its pro-inflammatory effect and dysregulated sympathetic nervous system activity may prevent further cardiovascular complication. Therefore, we recommend that treating an elevated level of leptin has broad therapeutic potential to inhibit the pathogenesis of chronic inflammatory disorders and associated further cardiovascular complications. Early therapeutic management of hyperleptinemia in obesity-associated inflammatory disorders has a cumulative therapeutic potential to manage complications of CVD.

\section{Abbreviations}

CVD, cardiovascular disease; IBD, inflammatory bowel disease; IL, interleukin; JAK2/STAT3, Janus kinase/activators of transcription-3; MetS, metabolic syndrome; RA, rheumatoid arthritis; SLE, systemic lupus erythematosus; TNF- $\alpha$, tumor necrosis factor-alpha. 


\section{Data Sharing Statement}

Data sharing is not applicable to this article because no data sets were generated or analyzed during the review.

\section{Acknowledgment}

We would like to acknowledge Mr Tadese Asemamaw for his great support regard to proofreading, language and grammatical problems improving this review article.

\section{Author Contributions}

All authors made a significant contribution to the work reported, whether that is in the conception, study design, execution, acquisition of data, analysis and interpretation, or in all these areas; took part in drafting, revising or critically reviewing the article; gave final approval of the version to be published; agreed on the journal to which the article has been submitted; and agree to be accountable for all aspects of the work.

\section{Funding}

No funding source is available.

\section{Disclosure}

The authors report no conflicts of interest in this work.

\section{References}

1. Ekmen N, Helvaci A, Gunaldi M, Sasani H, Yildirmak ST. Leptin as an important link between obesity and cardiovascular risk factors in men with acute myocardial infarction. Indian Heart J. 2016;68 (2):132-137. doi:10.1016/j.ihj.2015.07.032

2. Smith U. Is leptin coming back? A short introduction to the presentations in this symposium session at the 2015 annual meeting of the EASD. Diabetologia. 2016;59(5):918-919. doi:10.1007/s00125-0163894-7

3. Quarta C, Sánchez-Garrido MA, Tschöp MH, Clemmensen C. Renaissance of leptin for obesity therapy. Diabetologia. 2016;59 (5):920-927. doi:10.1007/s00125-016-3906-7

4. Flier JS, Maratos-Flier E. Leptin's physiologic role: does the emperor of energy balance have no clothes? Cell Metab. 2017;26(1):24-26. doi:10.1016/j.cmet.2017.05.013

5. Simonds SE, Cowley MA. Leptin effects on DAT neurons to control energy homeostasis. Endocrinology. 2017;158(12):4126-4128. doi:10.1210/en.2017-00820

6. Maffei M, Giordano A. Leptin, the brain and energy homeostasis: from an apparently simple to a highly complex neuronal system. Rev Endocr Metab Disord. 2021;22:1-15. doi:10.1007/s11154-02109629-1

7. Lee NJ, Qi Y, Enriquez RF, et al. Energy partitioning between fat and bone mass is controlled via a hypothalamic leptin/NPY relay Int J Obes. 2020;44(10):2149-2164. doi:10.1038/s41366-020-0550-6

8. Fasshauer M, Blüher M. Adipokines in health and disease. Trends Pharmacol Sci. 2015;36(7):461-470. doi:10.1016/j.tips.2015.04.014
9. Faulkner JL, Bruder-Nascimento T, de Chantemèle EJB. The regulation of aldosterone secretion by leptin: implications in obesity-related cardiovascular disease. Curr Opin Nephrol Hypertens. 2018;27(2):63. doi:10.1097/MNH.0000000000000384

10. Frühbeck G, Catalán V, Rodríguez A, et al. Adiponectin-leptin ratio is a functional biomarker of adipose tissue inflammation. Nutrients. 2019;11(2):454. doi:10.3390/nu11020454

11. Zonneveld M, Noordam R, van der Grond J, et al. Interplay of circulating leptin and obesity in cognition and cerebral volumes in older adults. Peptides. 2021;135:170424. doi:10.1016/j. peptides.2020.170424

12. Fatel EC, Rosa FT, Dichi I, Dichi I. Adipokines in rheumatoid arthritis. Adv Rheumatol. 2018;58. doi:10.1186/s42358-0180026-8

13. La Cava A. Leptin in inflammation and autoimmunity. Cytokine. 2017;98:51-58. doi:10.1016/j.cyto.2016.10.011

14. Pérez-Pérez A, Sánchez-Jiménez F, Vilariño-García T, SánchezMargalet V. Role of leptin in inflammation and vice versa. Int J Mol Sci. 2020;21(16):5887. doi:10.3390/ijms21165887

15. Baran A, Flisiak I, Jaroszewicz J, Świderska M. Effect of psoriasis activity on serum adiponectin and leptin levels. $A d v$ Dermatol Allergol. 2015;2(2):101. doi:10.5114/pdia.2014.40960

16. Cataldi C, Mari NL, Lozovoy MAB, et al. Proinflammatory and anti-inflammatory cytokine profiles in psoriasis: use as laboratory biomarkers and disease predictors. Inflam Res. 2019;68 (7):557-567. doi:10.1007/s00011-019-01238-8

17. Hwang J, Yoo JA, Yoon $\mathrm{H}$, et al. The role of leptin in the association between obesity and psoriasis. Biomol Ther (Seoul). 2021;29(1):11. doi:10.4062/biomolther.2020.054

18. Yu Y, Liu Y, Shi F-D, Zou H, Matarese G, La Cava A. Cutting edge: leptin-induced ROR $\gamma t$ expression in CD4+ T cells promotes Th17 responses in systemic lupus erythematosus. J Immunol. 2013;190(7):3054-3058. doi:10.4049/jimmunol.1203275

19. Mohammed SF, Abdalla MA, Ismaeil WM, Sheta MM. Serum leptin in systemic lupus erythematosus patients: its correlation with disease activity and some disease parameters. Egypt Rheumatol. 2018;40(1):23-27. doi:10.1016/j.ejr.2017.06.005

20. Yuan Q, Zhang L, Tian Y, Li W, Li X, Lu Z. Circulating leptin level, soluble leptin receptor level and their gene polymorphism in patients with systemic lupus erythematosus: a systematic review and meta-analysis. Clin Exp Rheumatol. 2020;38:1238-1246.

21. Popa C, Netea MG, Radstake TR, van Riel PL, Barrera P, van der Meer JW. Markers of inflammation are negatively correlated with serum leptin in rheumatoid arthritis. Ann Rheum Dis. 2005;64 (8):1195-1198. doi:10.1136/ard.2004.032243

22. Cordero-Barreal A, González-Rodríguez M, Ruiz-Fernández C, et al. An update on the role of leptin in the immuno-metabolism of cartilage. Int $J$ Mol Sci. 2021;22(5):2411. doi:10.3390/ ijms 22052411

23. Xue B, Yu Y, Zhang Z, et al. Leptin mediates high-fat diet sensitization of angiotensin II-elicited hypertension by upregulating the brain renin-angiotensin system and inflammation. Hypertension. 2016;67(5):970-976. doi:10.1161/ HYPERTENSIONAHA.115.06736

24. Meek TH, Morton GJ. The role of leptin in diabetes: metabolic effects. Diabetologia. 2016;59(5):928-932. doi:10.1007/s00125016-3898-3

25. Xu Y, Chang JT, Myers MG, Xu Y, Tong Q. Euglycemia restoration by central leptin in type 1 diabetes requires STAT3 signaling but not fast-acting neurotransmitter release. Diabetes. 2016;65 (4):1040-1049. doi:10.2337/db15-1160

26. Belaid-Choucair Z, Hermine O, Montes M, Garrido-Fleury C, Seigneuric R, Marcion G. Polypeptides capable of inhibiting the binding between leptin and neuropilin-1. Google Patents. 2018. 
27. Lekva T, Michelsen AE, Aukrust P, Henriksen T, Bollerslev J, Ueland T. Leptin and adiponectin as predictors of cardiovascular risk after gestational diabetes mellitus. Cardiovasc Diabetol. 2017;16(1):5. doi:10.1186/s12933-016-0492-4

28. Bednarska-Makaruk M, Graban A, Wiśniewska A, et al. Association of adiponectin, leptin and resistin with inflammatory markers and obesity in dementia. Biogerontology. 2017;18 (4):561-580. doi:10.1007/s10522-017-9701-0

29. Anche P, Maiya GA, Kamath SU, Shastry BA. Influence of a 12-week physical activity program on leptin resistance in metabolic syndrome: a preliminary study. Int J Diabetes Dev Ctries. 2021;1-7.

30. Frithioff-Bøjsøe C, Lund MA, Lausten-Thomsen U, et al. Leptin, adiponectin, and their ratio as markers of insulin resistance and cardiometabolic risk in childhood obesity. Pediatr Diabetes. 2020;21(2):194-202. doi:10.1111/pedi.12964

31. Bungau S, Behl T, Tit DM, et al. Interactions between leptin and insulin resistance in patients with prediabetes, with and without NAFLD. Exp Ther Med. 2020;20(6):1. doi:10.3892/ etm.2020.9327

32. Kumar R, Mal K, Razaq MK, et al. Association of leptin with obesity and insulin resistance. Cureus. 2020;12(12).

33. Uranga RM, Keller JN. The complex interactions between obesity, metabolism and the brain. Front Neurosci. 2019;13:513.

34. Giordano A, Frontini A, Cinti S. Convertible visceral fat as a therapeutic target to curb obesity. Nat Rev Drug Discov. 2016;15(6):405-424.

35. Hoffmann A, Ebert T, Klöting N, et al. Leptin dose-dependently decreases atherosclerosis by attenuation of hypercholesterolemia and induction of adiponectin. Biochimica et Biophysica Acta. 2016;1862(1):113-120. doi:10.1016/j.bbadis.2015.10.022

36. Kain D, Simon AJ, Greenberg A, Zvi DB, Gilburd B, Schneiderman J. Cardiac leptin overexpression in the context of acute MI and reperfusion potentiates myocardial remodeling and left ventricular dysfunction. PLoS One. 2018;13(10):e0203902. doi:10.1371/journal.pone.0203902

37. Rahmani A, Toloueitabar Y, Mohsenzadeh Y, Hemmati R, Sayehmiri K, Asadollahi K. Association between plasma leptin/ adiponectin ratios with the extent and severity of coronary artery disease. BMC Cardiovasc Disord. 2020;20(1):1-9. doi:10.1186/ s12872-020-01723-7

38. Payne GA, Kohr MC, Tune JD. Epicardial perivascular adipose tissue as a therapeutic target in obesity-related coronary artery disease. Br J Pharmacol. 2012;165(3):659-669. doi:10.1111/ j.1476-5381.2011.01370.x

39. Koh KK, Park SM, Quon MJ. Leptin and cardiovascular disease: response to therapeutic interventions. Circulation. 2008;117 (25):3238-3249. doi:10.1161/CIRCULATIONAHA.107.741645

40. Chen M-C, Wang J-H, Lee C-J, Hsu B-G. association between hyperleptinemia and cardiovascular outcomes in patients with coronary artery disease. Ther Clin Risk Manag. 2018;14:1855. doi:10.2147/TCRM.S172231

41. Cross M, Smith E, Hoy D, et al. The global burden of rheumatoid arthritis: estimates from the global burden of disease 2010 study. Ann Rheum Dis. 2014.

42. Ungurianu A, Margină D, Grădinaru D, et al. Lipoprotein redox status evaluation as a marker of cardiovascular disease risk in patients with inflammatory disease. Mol Med Rep. 2017;15 (1):256-262. doi:10.3892/mmr.2016.5972

43. Dar L, Tiosano S, Watad A, et al. Are obesity and rheumatoid arthritis interrelated? Int $J$ Clin Pract. 2018;72(1):e13045. doi:10.1111/ijcp.13045

44. Scotece M, Conde J, López V, et al. Adiponectin and leptin: new targets in inflammation. Basic Clin Pharmacol Toxicol. 2014;114 (1):97-102. doi:10.1111/bcpt.12109
45. Otero M, Lago R, Gomez R, et al. Changes in plasma levels of fat-derived hormones adiponectin, leptin, resistin and visfatin in patients with rheumatoid arthritis. Ann Rheum Dis. 2006;65 (9):1198-1201. doi:10.1136/ard.2005.046540

46. de Souza Fatel EC, Rosa FT, Dichi I. Adipokines in rheumatoid arthritis. Adv Rheumatol. 2018;58(1):1-10. doi:10.1186/s42358018-0001-4

47. Rivera-Bahena CB, Xibillé-Friedmann D-X, González-Christen J, Carrillo-Vázquez SM, Montiel-Hernández JL. Peripheral blood leptin and resistin levels as clinical activity biomarkers in mexican rheumatoid arthritis patients. Reumatol Clin. 2016;12 (6):323-326. doi:10.1016/j.reuma.2015.11.011

48. MacDonald IJ, Liu S-C, Huang C-C, Kuo S-J, Tsai C-H, Tang C-H. Associations between adipokines in arthritic disease and implications for obesity. Int J Mol Sci. 2019;20(6):1505. doi:10.3390/ijms20061505

49. Gonzalez-Gay M, Garcia-Unzueta M, Berja A, et al. Anti-TNFalpha therapy does not modulate leptin in patients with severe rheumatoid arthritis. Clin Exp Rheumatol. 2009;27(2):222-228.

50. Toussirot E, Marotte H, Mulleman D, et al. Increased high molecular weight adiponectin and lean mass during tocilizumab treatment in patients with rheumatoid arthritis: a 12-month multicentre study. Arthritis Res Ther. 2020;22(1):1-13. doi:10.1186/s13075-02002297-7

51. Pulito-Cueto V, Remuzgo-Martínez S, Genre F, et al. Anti-IL-6 therapy reduces leptin serum levels in patients with rheumatoid arthritis. Clin Exp Rheumatol. 2020.

52. Garcia-Bermudez M, González-Juanatey C, RodríguezRodríguez L, et al. Lack of association between LEP rs2167270 $(19 \mathrm{G}>\mathrm{A})$ polymorphism and disease susceptibility and cardiovascular disease in patients with rheumatoid arthritis. Clin Exp Rheumatol. 2011;29(2):293.

53. Skalska U, Kontny E. Adiponectin isoforms and leptin impact on rheumatoid adipose mesenchymal stem cells function. Stem Cells Int. 2016;2016:1-6. doi:10.1155/2016/6532860

54. Ozbalkan Z, Efe C, Cesur M, et al. An update on the relationships between rheumatoid arthritis and atherosclerosis. Atherosclerosis. 2010;212(2):377-382. doi:10.1016/j.atherosclerosis.2010.03.035

55. Francisco V, Pino J, Campos-Cabaleiro V, et al. Obesity, fat mass and immune system: role for leptin. Front Physiol. 2018;9:640. doi:10.3389/fphys.2018.00640

56. Crispino N, Ciccia F. JAK/STAT pathway and nociceptive cytokine signalling in rheumatoid arthritis and psoriatic arthritis. Clin Exp Rheumatol. 2020;39:668-675.

57. Seif F, Khoshmirsafa M, Aazami H, Mohsenzadegan M, Sedighi G, Bahar M. The role of JAK-STAT signaling pathway and its regulators in the fate of $\mathrm{T}$ helper cells. Cell Commun Signal. 2017;15(1):1-13. doi:10.1186/s12964-0170177-y

58. Simon AR, Rai U, Fanburg BL, Cochran BH. Activation of the JAK-STAT pathway by reactive oxygen species. Am J Physiol. 1998;275(6):C1640-C52. doi:10.1152/ajpcell.1998.275.6.C1640

59. Hou N, Luo JD. Leptin and cardiovascular diseases. Clin Exp Pharmacol Physiol. 2011;38(12):905-913. doi:10.1111/j.14401681.2011.05619.x

60. Seidel HM, Lamb P, Rosen J. Pharmaceutical intervention in the JAK/STAT signaling pathway. Oncogene. 2000;19 (21):2645-2656. doi:10.1038/sj.onc. 1203550

61. Tian G, Liang JN, Wang ZY, Zhou D. Emerging role of leptin in rheumatoid arthritis. Clin Exp Immunol. 2014;177(3):557-570. doi: $10.1111 /$ cei.12372

62. Wei ST, Sun YH, Zong SH, Xiang YB. Serum levels of IL-6 and TNF- $\alpha$ may correlate with activity and severity of rheumatoid arthritis. Med Sci Monit. 2015;21:4030-4038. 
63. Xie C, Chen Q. Adipokines: new therapeutic target for osteoarthritis? Curr Rheumatol Rep. 2019;21(12):1-9. doi:10.1007/s11926-019-0868-z

64. Faggioni R, Jones-Carson J, Reed DA, et al. Leptin-deficient (ob/ $\mathrm{ob})$ mice are protected from $\mathrm{T}$ cell-mediated hepatotoxicity: role of tumor necrosis factor $\alpha$ and IL-18. Proc Natl Acad Sci. 2000;97 (5):2367-2372. doi:10.1073/pnas.040561297

65. Dubey L, Hesong Z. Role of leptin in atherogenesis. Exp Clin Cardiol. 2006;11(4):269.

66. Zabeau L, Wauman J, Dam J, et al. A novel leptin receptor antagonist uncouples leptin's metabolic and immune functions. Cell Mol Life Sci. 2019;76(6):1201-1214. doi:10.1007/s00018019-03004-9

67. Wisłowska M, Rok M, Jaszczyk B, Stępień K, Cicha M. Serum leptin in rheumatoid arthritis. Rheumatol Int. 2007;27 (10):947-954. doi:10.1007/s00296-007-0335-4

68. Anne O, Murphy K. T-cell subsets in autoimmunity. Curr Opin Immunol. 1993;5(6):880-886. doi:10.1016/0952-7915(93)901007

69. Taha HA, Hozayen WG, Okasha AM, et al. Investigating the balance between Th17/Treg cells in rheumatoid arthritis and its association with disease activity. J Child Sci. 2019;9(01):e75-e83. doi:10.1055/s-0039-1693158

70. Kang Y, Park H-J, Kang M-I, et al. Adipokines, inflammation, insulin resistance, and carotid atherosclerosis in patients with rheumatoid arthritis. Arthritis Res Ther. 2013;15(6):R194. doi: $10.1186 / \operatorname{ar} 4384$

71. Lozovoy M, Simão A, Morimoto H, et al. Fish oil N-3 fatty acids increase adiponectin and decrease leptin levels in patients with systemic lupus erythematosus. Mar Drugs. 2015;13 (2):1071-1083. doi:10.3390/md13021071

72. Versini M, Tiosano S, Comaneshter D, Shoenfeld Y, Cohen AD, Amital H. Smoking and obesity in systemic lupus erythematosus: a cross-sectional study. Eur J Clin Invest. 2017;47(6):422-427. doi:10.1111/eci.12757

73. Li H-M, Zhang T-P, Leng R-X, et al. Emerging role of adipokines in systemic lupus erythematosus. Immunol Res. 2016;64 (4):820-830. doi:10.1007/s12026-016-8808-8

74. Chougule D, Nadkar M, Venkataraman K, et al. Adipokine interactions promote the pathogenesis of systemic lupus erythematosus. Cytokine. 2018;111:20-27. doi:10.1016/j.cyto.2018.08.002

75. Khairy N, Ezzat Y, Naeem N, Taha R, Wesam R. Atherosclerosis biomarkers in female systemic lupus erythematosus patients with and without cardiovascular diseases. Egypt Rheumatol. 2017;39 (1):7-12. doi:10.1016/j.ejr.2016.03.003

76. Santos F, Telles R, Lanna C, et al. Adipokines, tumor necrosis factor and its receptors in female patients with systemic lupus erythematosus. Lupus. 2017;26(1):10-16. doi:10.1177/ 0961203316646463

77. Giannelou M, Mavragani CP. Cardiovascular disease in systemic lupus erythematosus: a comprehensive update. J Autoimmun. 2017;82:1-12. doi:10.1016/j.jaut.2017.05.008

78. Michalska-Jakubus M, Sawicka K, Potembska E, Kowal M, Krasowska D. Clinical associations of serum leptin and leptin/ adiponectin ratio in systemic sclerosis. Adv Dermatol Allergol. 2019;36(3):325. doi:10.5114/ada.2018.75809

79. Yu Y, Fu S, Zhang X, et al. Leptin facilitates the differentiation of Th17 cells from MRL/Mp-Fas lpr lupus mice by activating NLRP3 inflammasome. Innate Immun. 2019;26:1753425919886643. doi: $10.1177 / 1753425919886643$

80. Moulton VR, Suarez-Fueyo A, Meidan E, Li H, Mizui M, Tsokos GC. Pathogenesis of human systemic lupus erythematosus: a cellular perspective. Trends Mol Med. 2017;23(7):615-635.

81. Ohl K, Tenbrock K. Regulatory $\mathrm{T}$ cells in systemic lupus erythematosus. Eur $J$ Immunol. 2015;45(2):344-355. doi:10.1002/eji.201344280
82. Kyriakou A, Patsatsi A, Sotiriadis D, Goulis D. Effects of treatment for psoriasis on circulating levels of leptin, adiponectin and resistin: a systematic review and meta-analysis. $\mathrm{Br} J$ Dermatol. 2018;179(2):273-281.

83. Boehncke W-H. Systemic inflammation and cardiovascular comorbidity in psoriasis patients: causes and consequences. Front Immunol. 2018;9:579. doi:10.3389/fimmu.2018.00579

84. Profumo E, Di Franco M, Buttari B, et al. Biomarkers of subclinical atherosclerosis in patients with autoimmune disorders. Mediators Inflamm. 2012;2012:1-8. doi:10.1155/2012/503942

85. Kunz M, Simon JC, Saalbach A. Psoriasis: obesity and fatty acids. Front Immunol. 2019;10:1807. doi:10.3389/ fimmu.2019.01807

86. Peluso R, Caso F, Tasso M, et al. Biomarkers of subclinical atherosclerosis in patients with psoriatic arthritis. Open Access Rheumatol. 2019;11:143. doi:10.2147/OARRR.S206931

87. Bai F, Zheng W, Dong Y, et al. Serum levels of adipokines and cytokines in psoriasis patients: a systematic review and meta-analysis. Oncotarget. 2018;9(1):1266. doi:10.18632/ oncotarget. 22260

88. Bavoso NC, Pinto JM, Soares MMS, MdS D, Teixeira Júnior AL. Psoriasis in obesity: comparison of serum levels of leptin and adiponectin in obese subjects-cases and controls. An Bras Dermatol. 2019;94(2):192-197. doi:10.1590/abd1806-4841.20197716

89. Pina T, Genre F, Lopez-Mejias R, et al. Relationship of Leptin with adiposity and inflammation and Resistin with disease severity in Psoriatic patients undergoing anti-TNF-alpha therapy. $J$ Eur Acad Dermatol Venereol. 2015;29(10):1995-2001. doi:10.1111/jdv.13131

90. Kong Y, Zhang S, Wu R, et al. New insights into different adipokines in linking the pathophysiology of obesity and psoriasis. Lipids Health Dis. 2019;18(1):171. doi:10.1186/ s12944-019-1115-3

91. Tazawa R, Uchida K, Fujimaki H, et al. Elevated leptin levels induce inflammation through IL-6 in skeletal muscle of aged female rats. BMC Musculoskelet Disord. 2019;20(1):199. doi:10.1186/s12891-019-2581-5

92. Vachatova S, Andrys C, Krejsek J, et al. Metabolic syndrome and selective inflammatory markers in psoriatic patients. J Immunol Res. 2016;2016:1-8. doi:10.1155/2016/5380792

93. McInnes IB, Illei GG, Danning CL, et al. IL-10 improves skin disease and modulates endothelial activation and leukocyte effector function in patients with psoriatic arthritis. J Immunol. 2001;167(7):4075-4082. doi:10.4049/jimmunol.167.7.4075

94. Dixon LJ, Kabi A, Nickerson KP, McDonald C. Combinatorial effects of diet and genetics on inflammatory bowel disease pathogenesis. Inflamm Bowel Dis. 2015;21(4):912-922. doi:10.1097/MIB.0000000000000289

95. Wang J, Pan Y, Cao Y, Zhou W, Lu J. Salidroside regulates the expressions of IL-6 and defensins in LPS-activated intestinal epithelial cells through NF-kB/MAPK and STAT3 pathways. Iran J Basic Med Sci. 2019;22(1):31.

96. Carvalho LG, Lima WG, Coelho LGV, Cardoso VN, Fernandes SOA. Circulating leptin levels as a potential biomarker in inflammatory bowel diseases: a systematic review and meta-analysis. Inflamm Bowel Dis. 2020.

97. Kreuter R, Wankell M, Ahlenstiel G, Hebbard L. The role of obesity in inflammatory bowel disease. Biochimica et Biophysica Acta. 2019;1865(1):63-72. doi:10.1016/j.bbadis.2018.10.020

98. Peng Y-J, Shen T-L, Chen Y-S, Mersmann HJ, Liu B-H, Ding S-T. Adiponectin and adiponectin receptor 1 overexpression enhance inflammatory bowel disease. J Biomed Sci. 2018;25 (1):24. doi:10.1186/s12929-018-0419-3

99. Liu D-R, Xu X-J, Yao S-K. Increased intestinal mucosal leptin levels in patients with diarrhea-predominant irritable bowel syndrome. World J Gastroenterol. 2018;24(1):46. doi:10.3748/ wjg.v24.i1.46 
100. Harper JW, Zisman TL. Interaction of obesity and inflammatory bowel disease. World J Gastroenterol. 2016;22(35):7868. doi:10.3748/wjg.v22.i35.7868

101. Karrasch T, Schaeffler A. Adipokines and the role of visceral adipose tissue in inflammatory bowel disease. Ann Gastroenterol. 2016;29(4):424. doi:10.20524/aog.2016.0077

102. Mamdouh M, Shaban S, Ibrahim Abushouk A, Zaki MMM, Ahmed OM, Abdel-Daim MM. Adipokines: potential therapeutic targets for vascular dysfunction in type II diabetes mellitus and obesity. J Diabetes Res. 2017;2017. doi:10.1155/2017/8095926

103. Teixeira TM, da Costa DC, Resende AC, Soulage CO, Bezerra FF, Daleprane JB. Activation of Nrf2-antioxidant signaling by 1, 25-dihydroxycholecalciferol prevents leptin-induced oxidative stress and inflammation in human endothelial cells. J Nutr. 2017;147(4):506-513. doi:10.3945/jn.116.239475

104. Bulum T, Lovrenčić MV, Tomić M, et al. Serum adipocytokines are associated with microalbuminuria in patients with type 1 diabetes and incipient chronic complications. Diabetes Metabol Syndr. 2019;13(1):496-499. doi:10.1016/j.dsx.2018.11.001

105. Gajewski M, Gajewska J, Rzodkiewicz P, Wojtecka-łukasik E. Influence of exogenous leptin on redox homeostasis in neutrophils and lymphocytes cultured in synovial fluid isolated from patients with rheumatoid arthritis. Reumatologia. 2016;3(3):103. doi:10.5114/reum.2016.61209

106. Dervišević A, Resić H, Sokolović Š, et al. Leptin is associated with disease activity but not with anthropometric indices in rheumatoid arthritis patients. Arch Med Sci. 2018;14(5):1080. doi:10.5114/aoms.2017.65080

107. Tsiotra PC, Boutati E, Dimitriadis G, Raptis SA. High insulin and leptin increase resistin and inflammatory cytokine production from human mononuclear cells. Biomed Res Int. 2012;2013. doi: $10.1155 / 2013 / 487081$

108. Wu X, Yu T, Ji N, et al. IL6R inhibits viability and apoptosis of pancreatic beta-cells in type 2 diabetes mellitus via regulation by miR-22 of the JAK/STAT signaling pathway. Diabetes Metabol Syndr Obes. 2019;12:1645. doi:10.2147/DMSO.S211700

109. Moshapa FT, Riches-Suman K, Palmer TM. Therapeutic targeting of the proinflammatory IL-6-JAK/STAT signalling pathways responsible for vascular restenosis in type 2 diabetes mellitus. Cardiol Res Pract. 2019;2019:1-15. doi:10.1155/2019/9846312

110. Sanchez-Margalet V, Martin-Romero C. Human leptin signaling in human peripheral blood mononuclear cells: activation of the JAK-STAT pathway. Cell Immunol. 2001;211(1):30-36. doi:10.1006/cimm.2001.1815

111. Procaccini C, Lourenco EV, Matarese G, Cava AL. Leptin signaling: a key pathway in immune responses. Curr Signal Transduct Ther. 2009;4(1):22-30. doi:10.2174/157436209787048711

112. Xu D, Yin C, Wang S, Xiao Y. JAK-STAT in lipid metabolism of adipocytes. Jak-Stat. 2013;2(4):e27203. doi:10.4161/ jkst. 27203

113. Artigas L, Coma M, Matos-Filipe $\mathrm{P}$, et al. In-silico drug repurposing study predicts the combination of pirfenidone and melatonin as a promising candidate therapy to reduce SARS-CoV-2 infection progression and respiratory distress caused by cytokine storm. PLoS One. 2020;15(10):e0240149. doi:10.1371/journal.pone.0240149

114. Vauthier V, Roujeau C, Chen P, et al. Endospanin1 affects oppositely body weight regulation and glucose homeostasis by differentially regulating central leptin signaling. Mol Metabol. 2017;6 (1):159-172. doi:10.1016/j.molmet.2016.10.009

115. Chiba T, Shinozaki S, Nakazawa T, et al. Leptin deficiency suppresses progression of atherosclerosis in apoE-deficient mice. Atherosclerosis. 2008;196(1):68-75. doi:10.1016/j. atherosclerosis.2007.01.040
116. D'souza AM, Johnson JD, Clee SM, Kieffer TJ. Suppressing hyperinsulinemia prevents obesity but causes rapid onset of diabetes in leptin-deficient Lepob/ob mice. Mol Metabol. 2016;5 (11):1103-1112. doi:10.1016/j.molmet.2016.09.007

117. Szczesna M, Kirsz K, Misztal T, Zieba DA. Downregulation of $\mathrm{LRb}$ in $\mathrm{VMH} / \mathrm{DMH}$ during the second half of gestation and upregulation of SOCS-3 in ARC in late-pregnant ewesImplications for leptin resistance. Gen Comp Endocrinol. 2019;274:73-79. doi:10.1016/j.ygcen.2019.01.003

118. Reed AS, Unger EK, Olofsson LE, Piper ML, Myers MG, $\mathrm{Xu}$ AW. Functional role of suppressor of cytokine signaling 3 upregulation in hypothalamic leptin resistance and long-term energy homeostasis. Diabetes. 2010;59(4):894-906. doi:10.2337/ db09-1024

119. Engin A. Diet-induced obesity and the mechanism of leptin resistance. Obesity Lipotox. 2017;381-397.

120. Münzberg H. Leptin-signaling pathways and leptin resistance. Front Eating Weight Regulation. 2010;63:123-132.

121. Gruzdeva O, Borodkina D, Uchasova E, Dyleva Y, Barbarash O. Leptin resistance: underlying mechanisms and diagnosis. Diabetes Metabol Syndr Obes. 2019;12:191. doi:10.2147/ DMSO.S182406

122. Crujeiras AB, Carreira MC, Cabia B, Andrade S, Amil M, Casanueva FF. Leptin resistance in obesity: an epigenetic landscape. Life Sci. 2015;140:57-63. doi:10.1016/j. lfs.2015.05.003

123. Kennedy JI, Askelund KJ, Premkumar R, et al. Leptin is associated with persistence of hyperglycemia in acute pancreatitis: a prospective clinical study. Medicine. 2016;95(6):e2382. doi:10.1097/MD.0000000000002382

124. Li X, Liu X, Wang Y, et al. Intervertebral disc degeneration in mice with type II diabetes induced by leptin receptor deficiency. BMC Musculoskelet Disord. 2020;21(1):1-10.

125. Zhu D, Yan Q, Li Y, Liu J, Liu H, Jiang Z. Effect of konjac mannan oligosaccharides on glucose homeostasis via the improvement of insulin and leptin resistance in vitro and in vivo. Nutrients. 2019;11(8):1705. doi:10.3390/nu11081705

126. Münzberg H, Björnholm M, Bates S, Myers M. Leptin receptor action and mechanisms of leptin resistance. Cell Mol Life Sci. 2005;62(6):642. doi:10.1007/s00018-004-4432-1

127. Denroche HC, Kwon MM, Quong WL, et al. Leptin induces fasting hypoglycaemia in a mouse model of diabetes through the depletion of glycerol. Diabetologia. 2015;58(5):1100-1108. doi:10.1007/s00125-015-3529-4

128. Platt TL, Beckett TL, Kohler K, Niedowicz DM, Murphy MP. Obesity, diabetes, and leptin resistance promote tau pathology in a mouse model of disease. Neuroscience. 2016;315:162-174. doi:10.1016/j.neuroscience.2015.12.011

129. Perry RJ, Petersen KF, Shulman GI. Pleotropic effects of leptin to reverse insulin resistance and diabetic ketoacidosis. Diabetologia. 2016;59(5):933-937. doi:10.1007/s00125-016-3909-4

130. Yu B, Cai D. Neural programmatic role of leptin, TNF $\alpha$, melanocortin, and glutamate in blood pressure regulation vs obesityrelated hypertension in male C57BL/6 mice. Endocrinology. 2017;158(6):1766-1775. doi:10.1210/en.2016-1872

131. Huby A-C, Otvos JL, Belin de Chantemèle EJ. Leptin induces hypertension and endothelial dysfunction via aldosterone-dependent mechanisms in obese female mice. Hypertension. 2016;67(5):1020-1028. doi:10.1161/ HYPERTENSIONAHA.115.06642

132. Ghaedian MM, Nazari Jaz A, Momeni M, Ghaedian T, Samiei N. Plasma leptin level is positively associated with blood pressure measures independent of gender and BMI. Clin Exp Hypertens. 2020;42(1):31-35. doi:10.1080/10641963.2018.1557684 
133. Simonds SE, Pryor JT, Ravussin E, et al. Leptin mediates the increase in blood pressure associated with obesity. Cell. 2014;159 (6):1404-1416. doi:10.1016/j.cell.2014.10.058

134. Ozata M, Ozdemir IC, Licinio J. Human leptin deficiency caused by a missense mutation: multiple endocrine defects, decreased sympathetic tone, and immune system dysfunction indicate new targets for leptin action, greater central than peripheral resistance to the effects of leptin, and spontaneous correction of leptin-mediated defects. J Clin Endocrinol Metab. 1999;84 (10):3686-3695.

135. Bell BB, Rahmouni K. Leptin as a mediator of obesity-induced hypertension. Curr Obes Rep. 2016;5(4):397-404. doi:10.1007/ s13679-016-0231-x

136. Li Y-X, Zhang Q, Shang X-M, et al. Association of two well-defined polymorphisms in leptin and leptin receptor genes with hypertension and circulating leptin: a meta-analysis. Arch Med Res. 2015;46(1):38-46. doi:10.1016/ j.arcmed.2014.11.012

137. Kusminski CM, Scherer PE. Leptin beyond the lipostat: key component of blood pressure regulation. Circ Res. 2015;116 (8):1293-1295. doi:10.1161/CIRCRESAHA.115.305937

138. Balasubramanian P, Hall D, Subramanian M. Sympathetic nervous system as a target for aging and obesity-related cardiovascular diseases. Geroscience. 2019;41(1):13-24. doi:10.1007/ s11357-018-0048-5

139. von Schnurbein J, Manzoor J, Brandt S, et al. Leptin is not essential for obesity-associated hypertension. Obes Facts. 2019;12(4):460-475. doi:10.1159/000501319

140. Jiang $\mathrm{P}$, Ma D, Wang $\mathrm{X}$, et al. Astragaloside IV prevents obesity-associated hypertension by improving pro-inflammatory reaction and leptin resistance. Mol Cells. 2018;41(3):244. doi:10.14348/molcells.2018.2156

141. Pandit R, Beerens S, Adan RA. Role of leptin in energy expenditure: the hypothalamic perspective. Am J Physiol. 2017;312(6): R938-R47. doi:10.1152/ajpregu.00045.2016

142. Myers MG, Cowley MA, Münzberg H. Mechanisms of leptin action and leptin resistance. Annu Rev Physiol. 2008;70:537-556. doi:10.1146/annurev.physiol.70.113006.100707

143. Guarino D, Nannipieri M, Iervasi G, Taddei S, Bruno RM. The role of the autonomic nervous system in the pathophysiology of obesity. Front Physiol. 2017;8:665. doi:10.3389/fphys.2017.00665

144. da Silva AA, Do Carmo JM, Wang Z, Hall JE. Melanocortin-4 receptors and sympathetic nervous system activation in hypertension. Curr Hypertens Rep. 2019;21(6):46. doi:10.1007/ s11906-019-0951-x

145. Cat AND, Friederich-Persson M, White A, Touyz RM. Adipocytes, aldosterone and obesity-related hypertension. $J \mathrm{Mol}$ Endocrinol. 2016;57(1):F7-F21. doi:10.1530/JME-16-0025

146. Xie D, Bollag WB. Obesity, hypertension and aldosterone: is leptin the link? J Endocrinol. 2016;230(1):F7-F11. doi:10.1530/ JOE-16-0160

147. Meier T, Gräfe K, Senn F, et al. Cardiovascular mortality attributable to dietary risk factors in 51 countries in the WHO European Region from 1990 to 2016: a systematic analysis of the Global Burden of Disease Study. Eur J Epidemiol. 2019;34(1):37-55. doi:10.1007/s10654-018-0473-x

148. Yu J, Tostanoski LH, Peter L, et al. DNA vaccine protection against SARS-CoV-2 in rhesus macaques. Science. 2020;369:806-811. doi:10.1126/science.abc6284

149. Gholikhani Darbroud R, Hajahmadi Poor Rafsanjani M, Mansouri F, Khaki Khatibi F, Ghojazadeh M. Decreased circulatory microRNA-4478 as a specifi c biomarker for diagnosing non-ST-segment elevation myocardial infarction (NSTEMI) and its association with soluble leptin receptor. Brat Med J. 2017;118 (11):684-690. doi:10.4149/BLL_2017 129
150. Yang H, Guo W, Li J, et al. Leptin concentration and risk of coronary heart disease and stroke: a systematic review and meta-analysis. PLoS One. 2017;12(3):e0166360. doi:10.1371/ journal.pone. 0166360

151. Lieb W, Sullivan LM, Harris TB, et al. Plasma leptin levels and incidence of heart failure, cardiovascular disease, and total mortality in elderly individuals. Diabetes Care. 2009;32(4):612-616. doi:10.2337/dc08-1596

152. Chait A, den Hartigh LJ. Adipose tissue distribution, inflammation and its metabolic consequences, including diabetes and cardiovascular disease. Front Cardiovasc Med. 2020;7.

153. Saxton SN, Clark BJ, Withers SB, Eringa EC, Heagerty AM. Mechanistic links between obesity, diabetes, and blood pressure: role of perivascular adipose tissue. Physiol Rev. 2019;99 (4):1701-1763. doi:10.1152/physrev.00034.2018

154. Chang L, Garcia-Barrio MT, Chen YE. Perivascular adipose tissue regulates vascular function by targeting vascular smooth muscle cells. Arterioscler Thromb Vasc Biol. 2020;40 (5):1094-1109. doi:10.1161/ATVBAHA.120.312464

155. Hu H, Garcia-Barrio M, Jiang Z-S, Chen YE, Chang L. Roles of perivascular adipose tissue in hypertension and atherosclerosis. Antioxid Redox Signal. 2021;34(9):736-749. doi:10.1089/ ars. 2020.8103

156. Loesch A, Dashwood MR. Nerve-perivascular fat communication as a potential influence on the performance of blood vessels used as coronary artery bypass grafts. J Cell Commun Signal. 2018;12 (1):181-191. doi:10.1007/s12079-017-0393-7

157. Wang D, Wang Z, Zhang L, Wang Y. Roles of cells from the arterial vessel wall in atherosclerosis. Mediators Inflamm. 2017;2017:1-9. doi:10.1155/2017/8135934

158. Qi X-Y, Qu S-L, Xiong W-H, Rom O, Chang L, Jiang Z-S. Perivascular adipose tissue (PVAT) in atherosclerosis: a double-edged sword. Cardiovasc Diabetol. 2018;17(1):1-20.

159. Che C, Dudick K, Shoemaker R. Cardiac hypertrophy with obesity is augmented after pregnancy in C57BL/6 mice. Biol Sex Differ. 2019;10(1):1-13. doi:10.1186/s13293-019-0269-z

160. Chen H, Li M, Liu L, Zhu D, Tian G. Telmisartan improves myocardial remodeling by inhibiting leptin autocrine activity and activating PPAR $\gamma$. Exp Biol Med. 2020;245(7):654-666. doi:10.1177/1535370220908215

161. Hall ME, Harmancey R, Stec DE. Lean heart: role of leptin in cardiac hypertrophy and metabolism. World J Cardiol. 2015;7 (9):511. doi:10.4330/wjc.v7.i9.511

162. Stangl K, Cascorbi I, Laule M, et al. Elevated serum leptin in patients with coronary artery disease: no association with the Trp64Arg polymorphism of the $\beta$ 3-adrenergic receptor. Int $J$ Obes. 2000;24(3):369. doi:10.1038/sj.ijo.0801159

163. Demiray G, Değirmencioğlu S, Uğurlu E, Yaren A. Effects of serum leptin and resistin levels on cancer cachexia in patients with advanced-stage non-small cell lung cancer. Clin Med Insights Oncol. 2017;11:1179554917690144. doi:10.1177/ 1179554917690144

164. Singhal A, Farooqi IS, Cole TJ, et al. Influence of leptin on arterial distensibility: a novel link between obesity and cardiovascular disease? Circulation. 2002;106(15):1919-1924. doi:10.1161/01.CIR.0000033219.24717.52

165. Hasty AH, Shimano H, Osuga J-I, et al. Severe hypercholesterolemia, hypertriglyceridemia, and atherosclerosis in mice lacking both leptin and the low density lipoprotein receptor. J Biol Chem. 2001;276(40):37402-37408. doi:10.1074/jbc.M010176200

166. Piemonti L, Calori G, Mercalli A, et al. Fasting plasma leptin, tumor necrosis factor- $\alpha$ receptor 2 , and monocyte chemoattracting protein 1 concentration in a population of glucose-tolerant and glucoseintolerant women: impact on cardiovascular mortality. Diabetes Care. 2003;26(10):2883-2889. doi:10.2337/diacare.26.10.2883 
167. Rajapurohitam V, Javadov S, Purdham DM, Kirshenbaum LA, Karmazyn M. An autocrine role for leptin in mediating the cardiomyocyte hypertrophic effects of angiotensin II and endothelin-1. J Mol Cell Cardiol. 2006;41(2):265-274. doi:10.1016/j.yjmcc.2006.05.001

168. Rajapurohitam V, Kilic A, Javadov S, Karmazyn M. Role of NF$\kappa \mathrm{B}$ and $\mathrm{p} 38$ MAPK activation in mediating angiotensin II and endothelin-1-induced stimulation in leptin production and cardiomyocyte hypertrophy. Mol Cell Biochem. 2012;366(12):287-297. doi:10.1007/s11010-012-1307-x

169. Bruder-Nascimento T, Kress TC, De Chantemele EJB. Recent advances in understanding lipodystrophy: a focus on lipodystrophy-associated cardiovascular disease and potential effects of leptin therapy on cardiovascular function. F1000Research. 2019;8:1756. doi:10.12688/f1000research. 20150.1

170. Francisco V, Ruiz-Fernández C, Pino J, et al. Adipokines: linking metabolic syndrome, the immune system, and arthritic diseases. Biochem Pharmacol. 2019;165:196-206. doi:10.1016/j.bcp.2019. 03.030

171. Abella V, Scotece M, Conde J, et al. Adipokines, metabolic syndrome and rheumatic diseases. $J$ Immunol Res. 2014;2014:1-14. doi:10.1155/2014/343746

172. Batún-Garrido JADJ, Salas-Magaña M, Juárez-Rojop IE. Association between leptin and IL-6 concentrations with cardiovascular risk in patients with rheumatoid arthritis. Clin Rheumatol. 2018;37(3):631-637. doi:10.1007/s10067-017-3897-x
173. Beltowski J. Leptin and atherosclerosis. Atherosclerosis. 2006;189(1):47-60. doi:10.1016/j.atherosclerosis.2006.03.003

174. Croca S, Rahman A. Atherosclerosis in systemic lupus erythematosus. Best Pract Res Clin Rheumatol. 2017;31 (3):364-372. doi:10.1016/j.berh.2017.09.012

175. Xu W-D, Zhang M, Zhang Y-J, Liu -S-S, Pan H-F, Ye D-Q. Association between leptin and systemic lupus erythematosus. Rheumatol Int. 2014;34(4):559-563. doi:10.1007/s00296-0132774-4

176. Tselios K, Sheane BJ, Gladman DD, Urowitz MB. Optimal monitoring for coronary heart disease risk in patients with systemic lupus erythematosus: a systematic review. $J$ Rheumatol. 2016;43 (1):54-65. doi:10.3899/jrheum. 150460

177. Lewandowski LB, Kaplan MJ. Update on cardiovascular disease in lupus. Curr Opin Rheumatol. 2016;28(5):468. doi:10.1097/ BOR.0000000000000307

178. Theocharidou E, Balaska A, Vogiatzis K, et al. Hypertrophic mesenteric adipose tissue may play a role in atherogenesis in inflammatory bowel diseases. Inflamm Bowel Dis. 2016;22 (9):2206-2212. doi:10.1097/MIB.0000000000000873

179. Zampeli E, Protogerou A, Stamatelopoulos K, et al. Predictors of new atherosclerotic carotid plaque development in patients with rheumatoid arthritis: a longitudinal study. Arthritis Res Ther. 2012;14(2):R44. doi:10.1186/ar3757

\section{Publish your work in this journal}

Diabetes, Metabolic Syndrome and Obesity: Targets and Therapy is an international, peer-reviewed open-access journal committed to the rapid publication of the latest laboratory and clinical findings in the fields of diabetes, metabolic syndrome and obesity research. Original research, review, case reports, hypothesis formation, expert opinion and commentaries are all considered for publication. The manuscript management system is completely online and includes a very quick and fair peer-review system, which is all easy to use. Visit http://www.dovepress.com/testimonials.php to read real quotes from published authors. 